\title{
مقومات الفكر التربوي الإسلامي في ظل المتغيرات (نظرة تحليلية في عو امل بناء الذات)
}

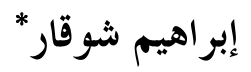

\section{مقدمة}

إن أي الخطاط حضاري للشعوب قد يعود بالأساس إلى نظمها التربوية، لأن

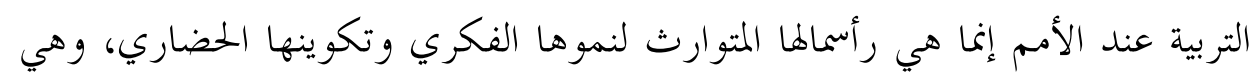

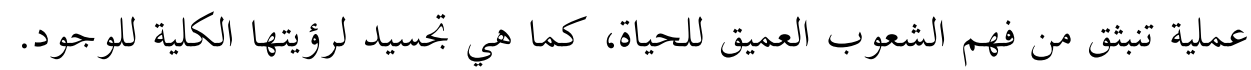

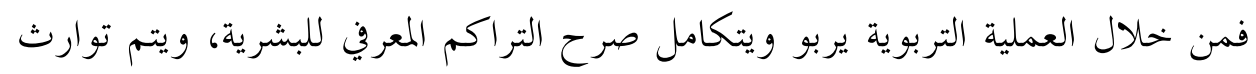

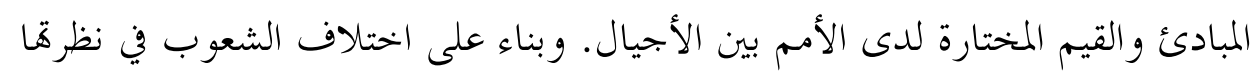

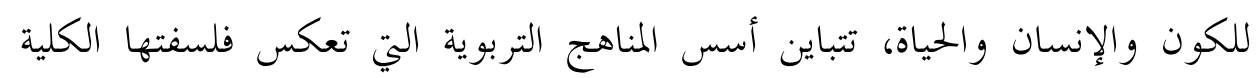
للوجود.

إن إعادة النظر في نظم فلسفة التربية الإسلامية من جهة، والتأمل المستمر في إنباء

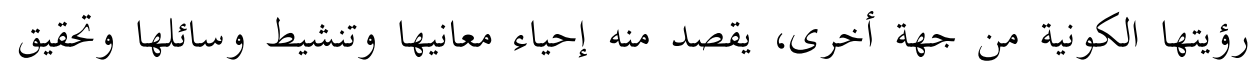

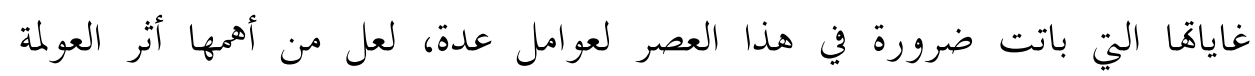

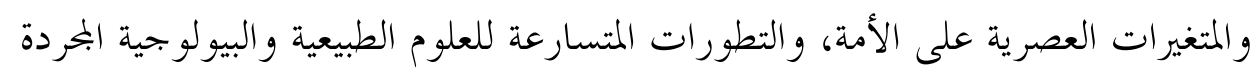

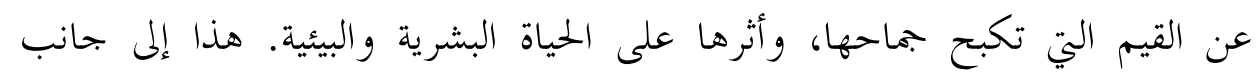

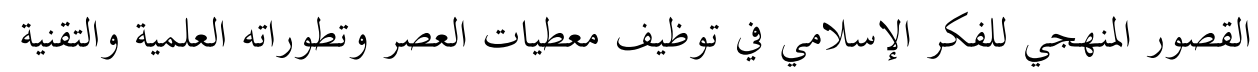

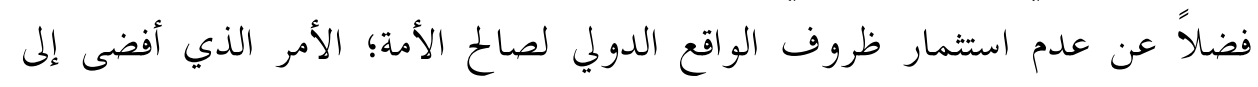

"إبــراهيم شوقار، دكتوراه في معارف الوحي، أستاذ مساعد لفلسفة العلوم بالجامعة الإسلامية العالمية، ماليزيا. Shogar@iiu.edu.my ينبغي التفطن إلى أن إلقاء تبعة الانطاط على التربويين ليس صواباً في جميع الأحوال، إنما القصد هنا بيان أهمية التربية ودورها في حياة الأمم. 
تخلفها عن القيام بكهمة رسالتها الكونية وعدم قدرةا على الإفادة من تاريخها البحيد،

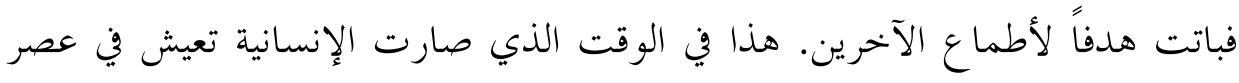

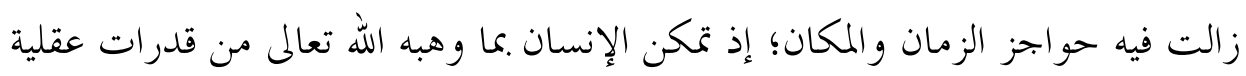

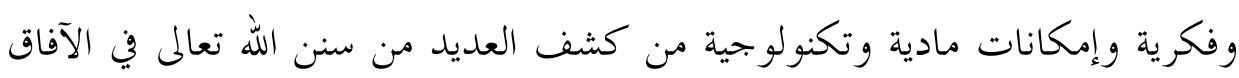

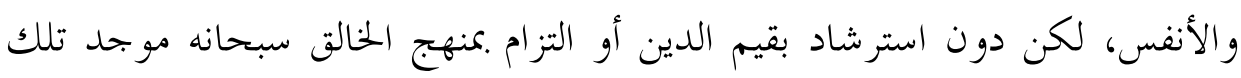

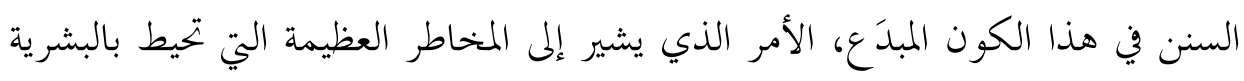

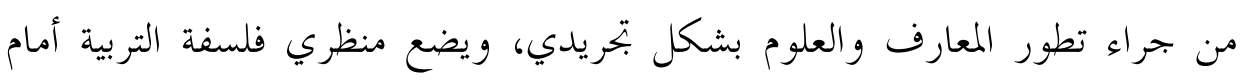

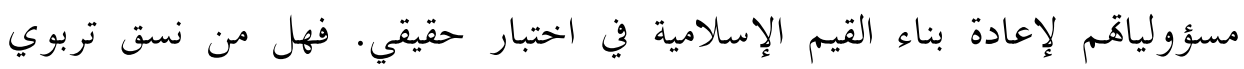

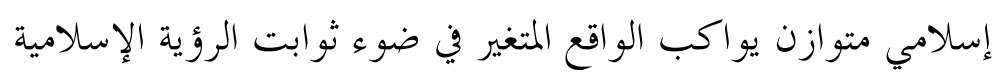

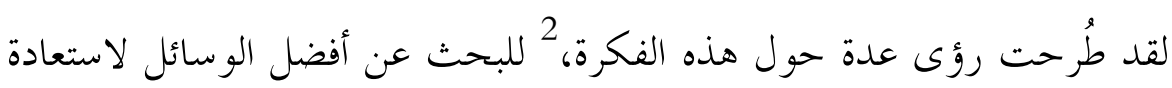

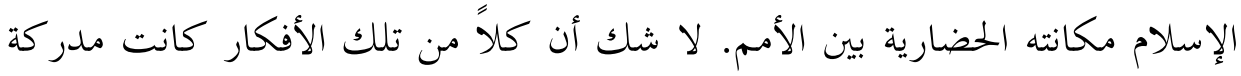

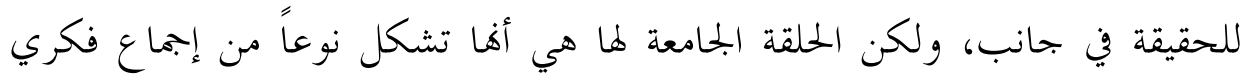

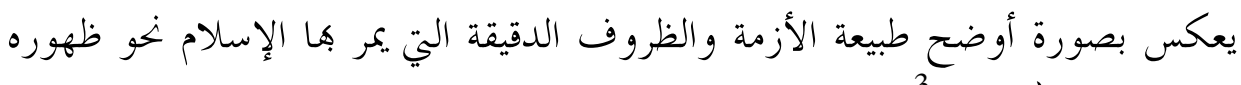
الكلي بإذن الله تعالى.

يدور محور هذا البحث حول مقومات الفكر التربوي في الإسلام، والهادف في

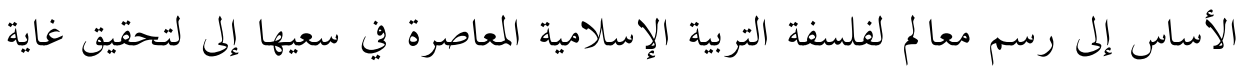

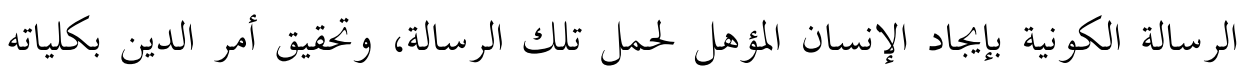

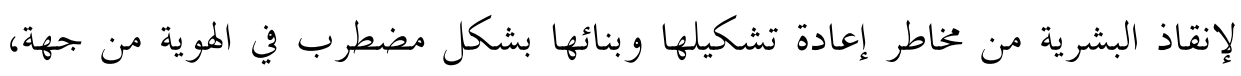

22 كُتسبت أعمـال عدة حاولت تشخيص الأزمة الفكرية للأمة من خلالل ربطها بالفكر التربوي، (راجع: مثلاً

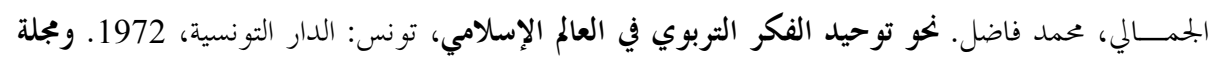

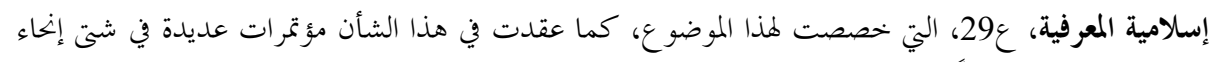

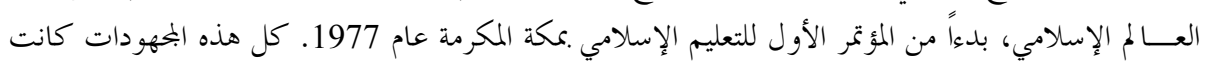

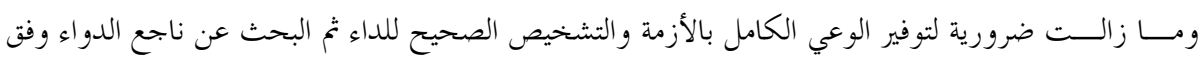
معطيات العصر. 33 انظـــ، شوقار، إبراهيم. "العولمة والعالية في ضوء سنن الله الكونية"، مجلة التجديد، ع 14 (أغسطس 2003)، 
وتبصير الأمة الإسلامية بدورها الأخلاقي الكبير في هذه العملية والتحديات العظيمة

$$
\text { التي تو اجهرا من جهة أخرى. }
$$

إن كليات الدين-النظرة الكونية الإسلامية- التي تنتظم في سلكها النظم الفكرية

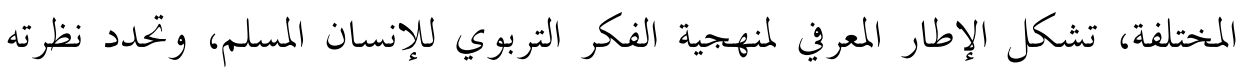

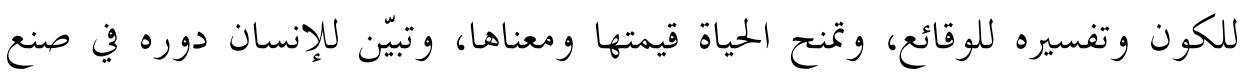

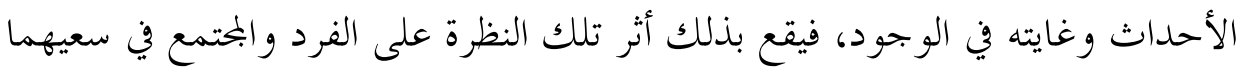

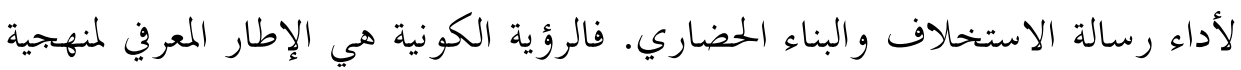

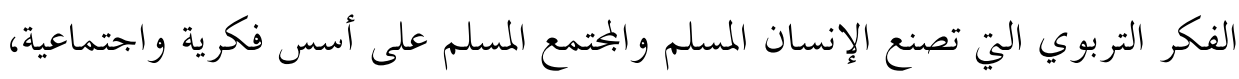

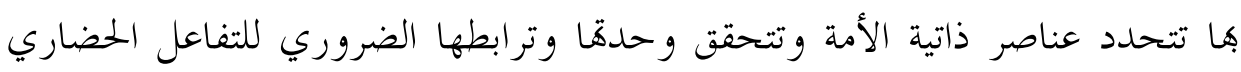
مع الشعوب وقيادةا إلى السلام والأمان.

\section{أولاً: الفكر التربوي والتصور الكلي}

يرى فلاسفة التربية أن العملية التربوية بمفهومها العام تبدأ بصورة لا شعورية منذ

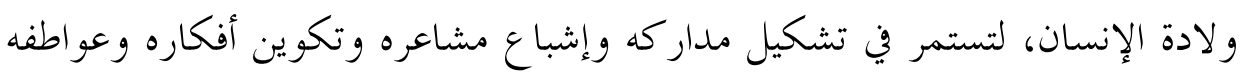

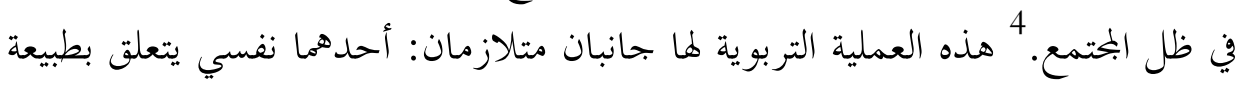

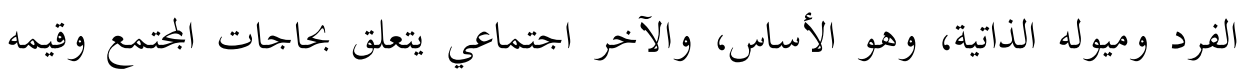

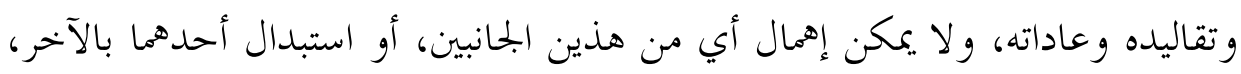

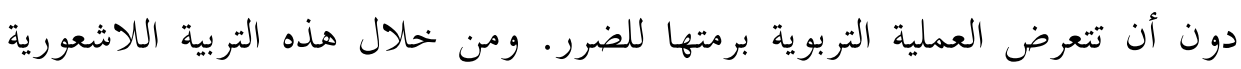

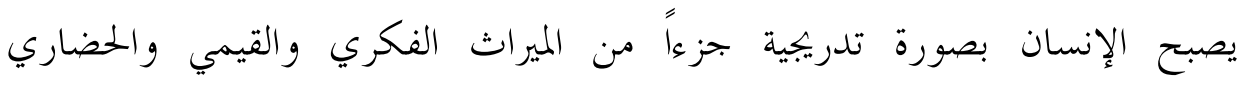
للمجتمع، وهي من الرسوخ بمكان، بحيث يستعصي على التربية النظامية (التعليم

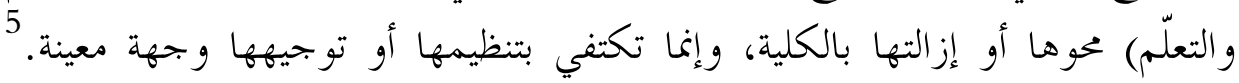

4

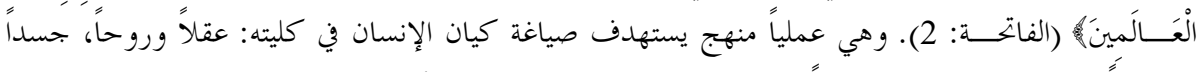

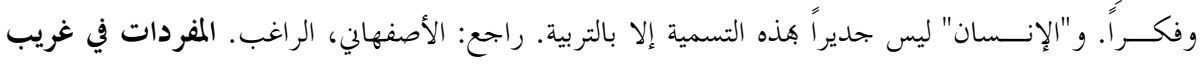

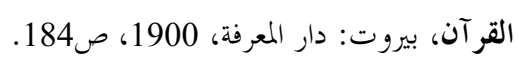

5 John Dewey (1859-1952), Philosophical Documents in Education, Roland F. Reed \& Tony W Johnson (editors), Longman (New York 2000) P.93. 
فالميراث الفكري القائم على التصور الكلي للمجتمع هو الذي يمدد مناهج التفكير العلمي للإنسان، بينما الميراث القيمي يحلد أنماط سلو كه وطبيعة تصرف لفاته.

من هذا تظهر بوضوح الصلة والارتباط الوثيق بين التربية والتصور الكلي للأمم. 6

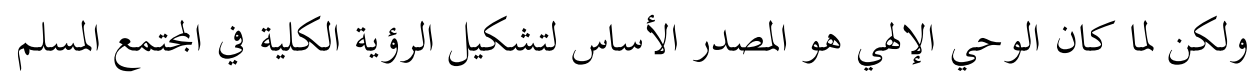

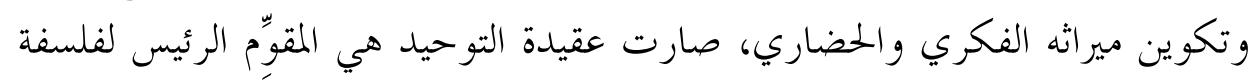
التربية في الإسلام. وتير أله الفري

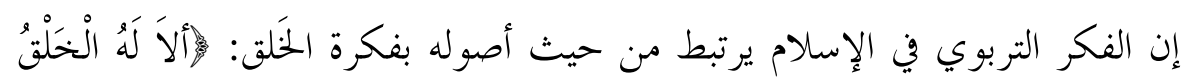

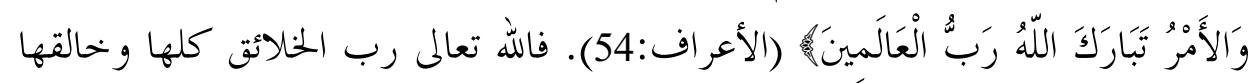

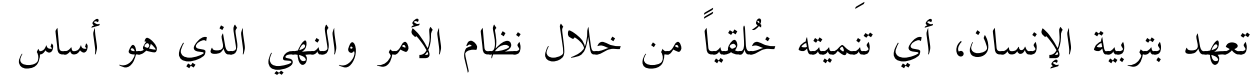

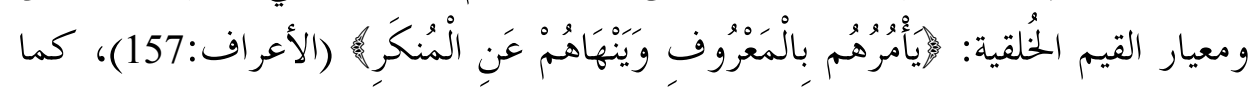

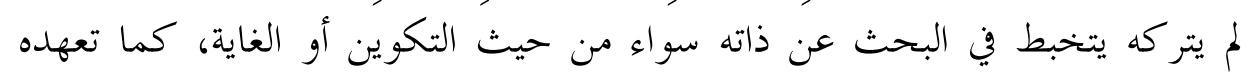

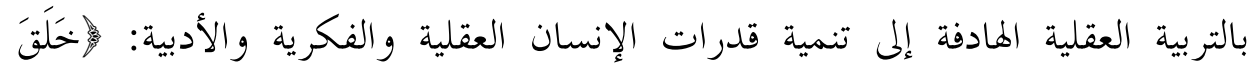

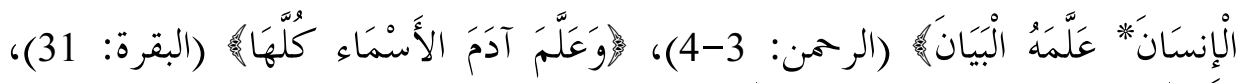

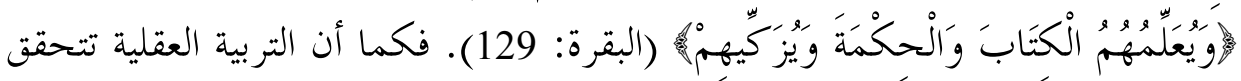

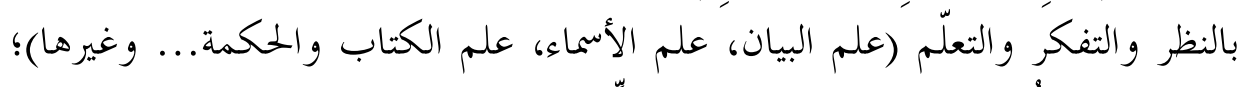

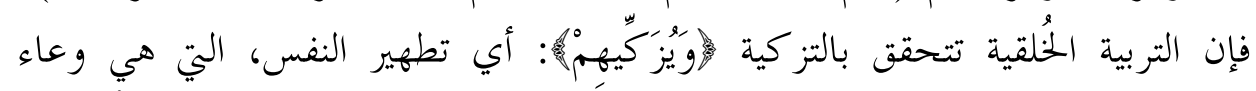

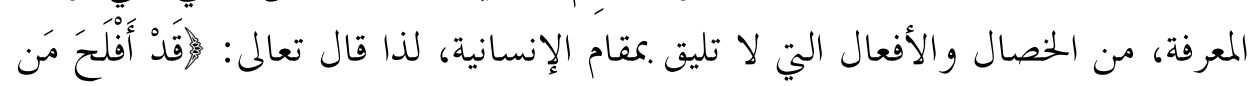

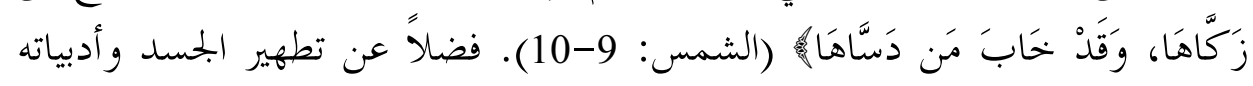

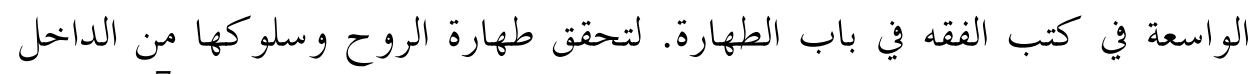

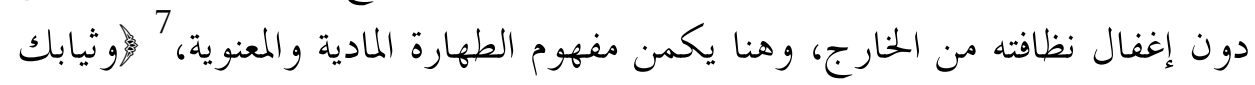
فطهر (المدثر: 4) بين المؤمن والكافر.

6 6راجع مزيداً من التفصيل للعلاقة بين التربية والتصور الكلي، الهاشي، السيد محمود. "النظرة الكونية أو الأساس

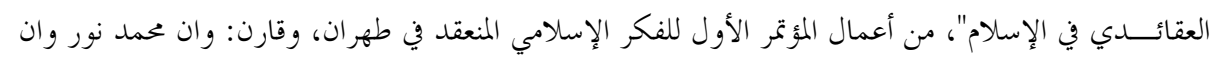

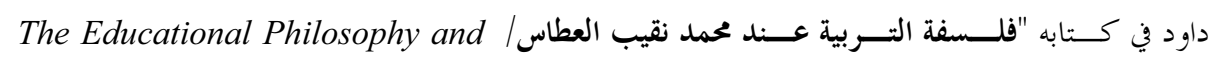
إن 7 Practice of Naquib Al-Attas

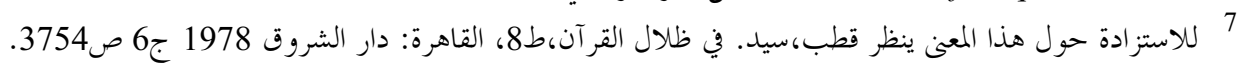


إن المعرفة والقيم أمران متلازمان في الفكر التربوي الإسلامي، فكلما ازداد

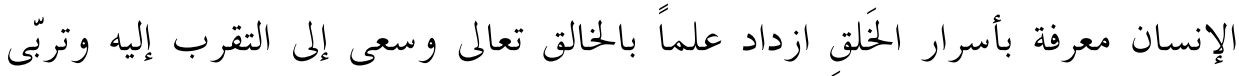

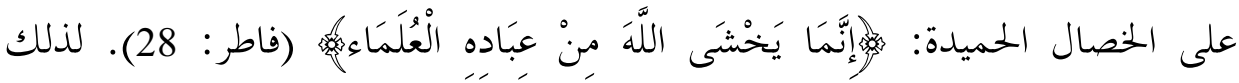
ذهب بعض المفكرين المسلمين في تعريف التربية بأذا "إدراك وتحقق بمواضع الأشياء في سُلم الخلائق، يُغرس تدرجياً في الإنسان بحيث يقوده إلى الإدراك التام والتحقق بمكانة الخالق في نظام الوجود."8 فالتصور الكلي هو الذي يحدد للتربية فلسفتها وإطارها المعرفي والقيمي، ويوفر رؤية واضحة عن الكون والإنسان والحياة، ويحدد الأهداف الاستراتيجية للعملية التربوية، بل يصوغ الإنسان والظروف المناسبة للمجتمع ليعيش في ترابط وانسجام.

إن ارتباط النظم التربوية للأمم بتصورها الكلي للوجود يقرر حقيقتين مهمتين

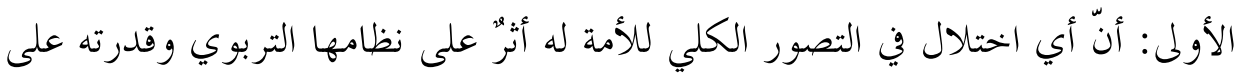
تحقيق غاياته الجوهرية، كما أنّ هافت النظم التربوية قد تقتضي إعادة النظر فيها من إنى

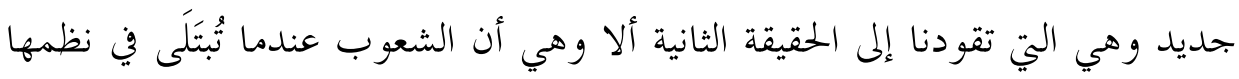

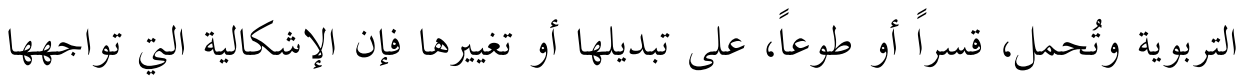
حينئذ ليست إشكالية نظم ومناهج تربوية وإنما إشكالية تصور كلي للوجود، وبالتالي أية محاولة من هذا القبيل يجب مقاو متها.

هاتان الحقيقتان هما التحدي السافر الذي يواجه أمة الإسلام اليوم في تقلّبها بين محاولة الحفاظ على أسس نظامها التربوي الموروث، الأسرة ورابطتها المتينة- المسجدقيم الدين...وغيرها، و بين إرهاصات عالم مادي مضطرب؛ مفعم بتطورات المعارف و تقلبات الأحداث.

8 Education is "recognition and acknowledgement, progressively instilled in to man, of the proper places of things in the order of creation, such that it leads to the recognition and acknowledgement of the proper place of God in the order of being and existence". AL- Attas, Muhammad Naquib. (1999) The Concept of Education in Islam, International institute of Islamic Thought and Civilization (ISTAC). PP. 15/26. 


\section{ثانياً: مقومات الفكر التربوي في الإسلام}

إن فلسفة التربية مهما تباينت وسائلها وتعددت غاياقا، تقوم على ركنين: أولهما

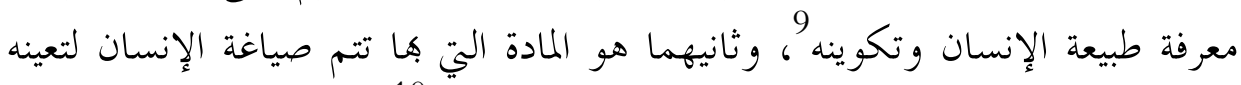

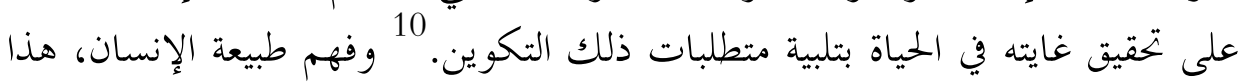

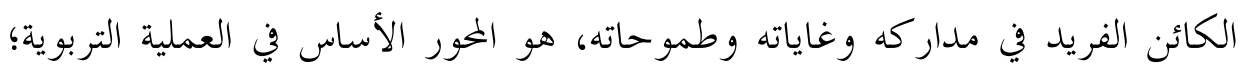

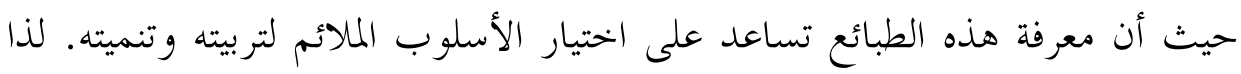

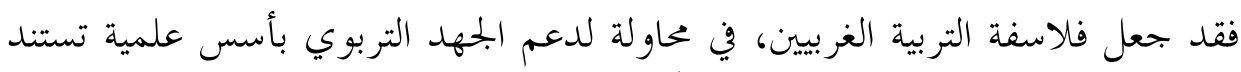

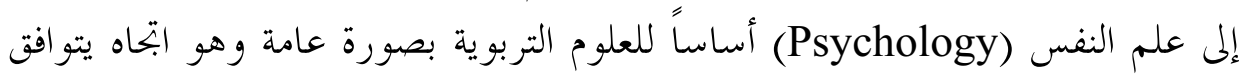

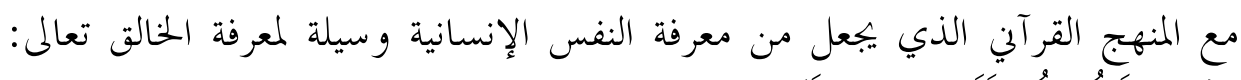

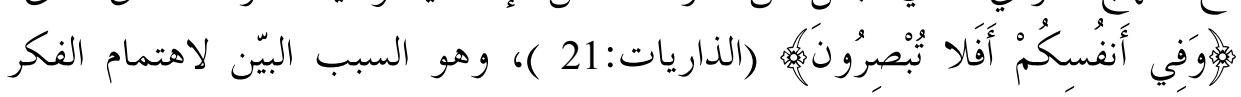

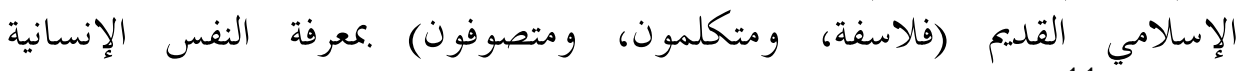
وطبائعها. 11 ولكن معرفة الطبيعة الإنسانية هنا لابد أن تستند إلى المفهوم القرآي

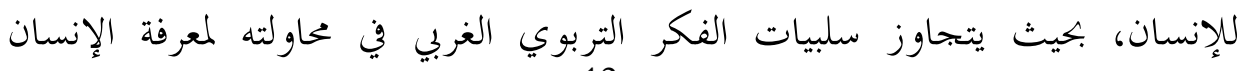
بإخضاعه لمنهج العلوم الطبيعية أسوة بالمادة. 12

ثَم عنصر آخر يطرحه القرآن لمعرفة الإنسان بصورة صحيحة، لم يفطن إليه

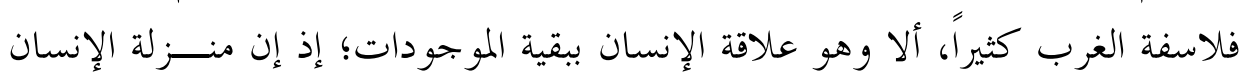
9 يرى الر اغب الأصغهاني، أن (الإنسان مر كب من جسم مدرك بالبصر ونفس مدر كة بالبصيرة)، واستشهد بقوله

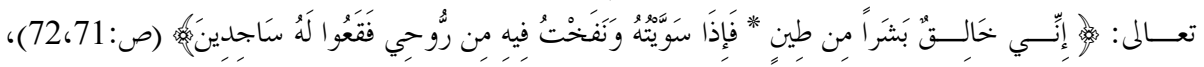

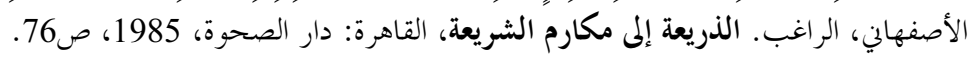
10

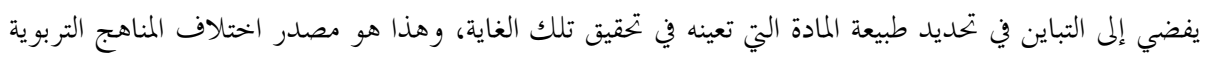
وفلسفتها.

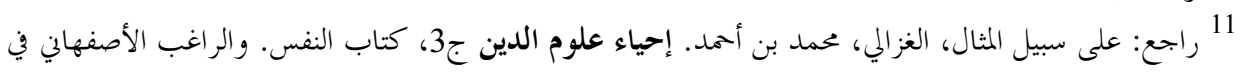

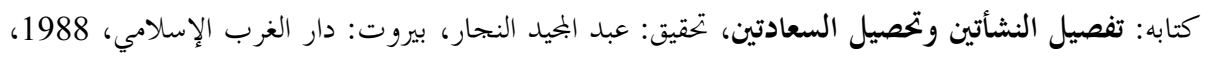
ص 61 وما بعدها.

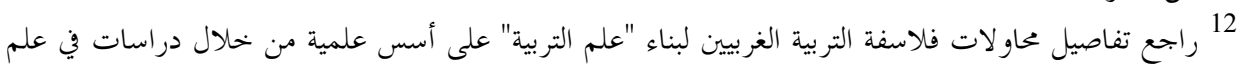

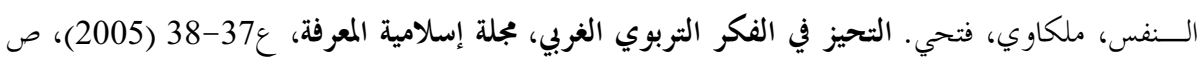




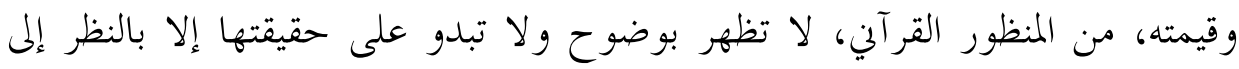

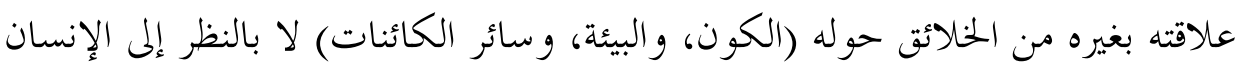

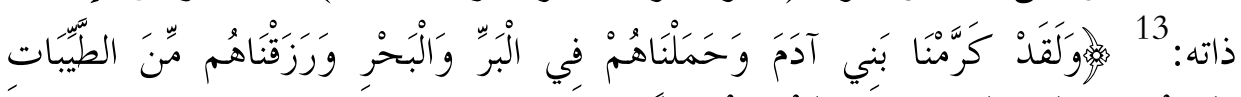

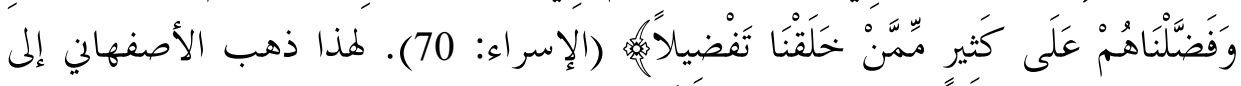

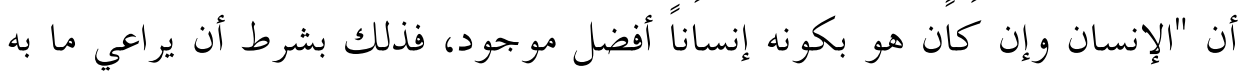

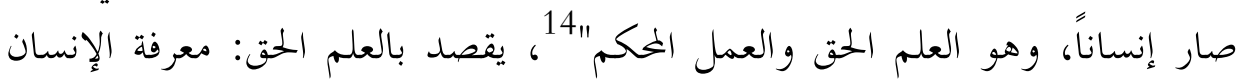

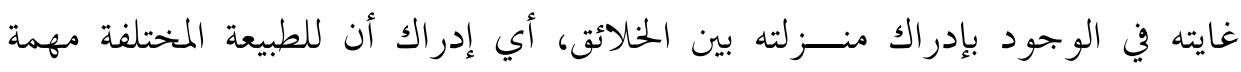

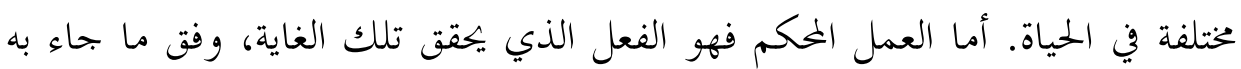

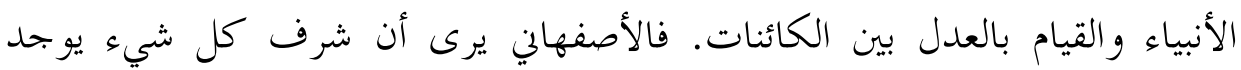

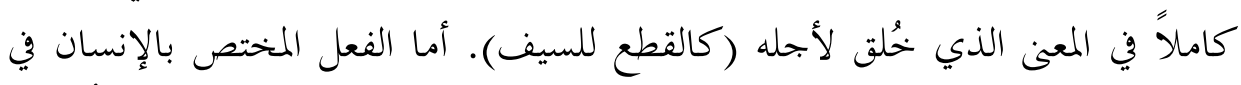

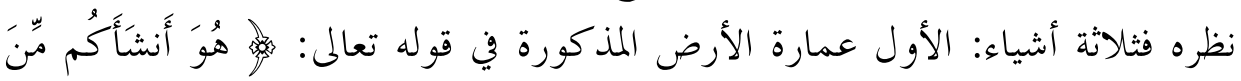

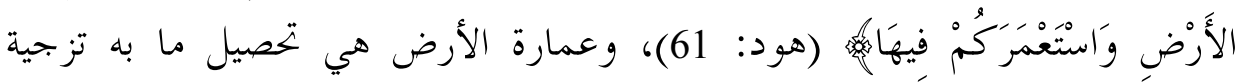

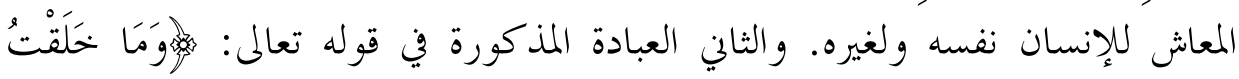

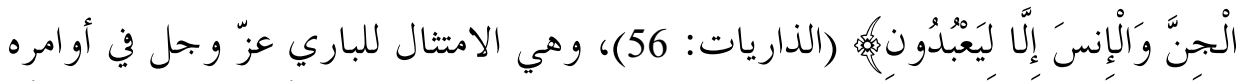

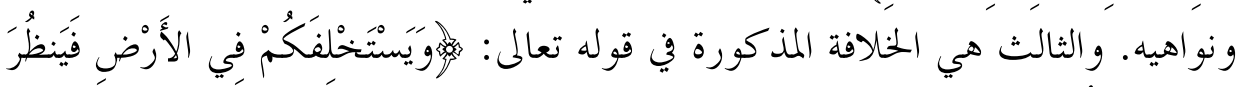

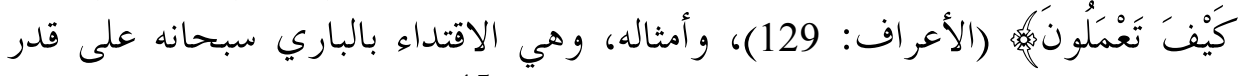
الطاقة البشرية في السياسة باستعمال مكارم الشريعة. 129

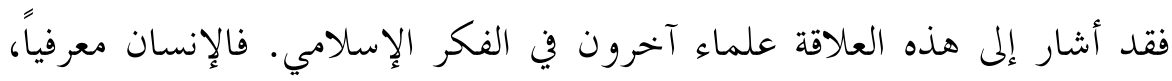

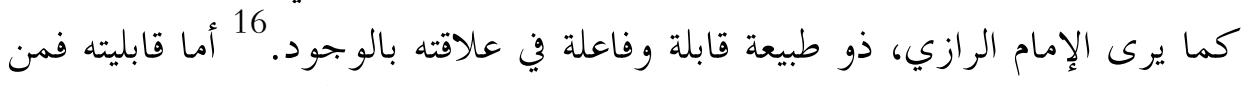

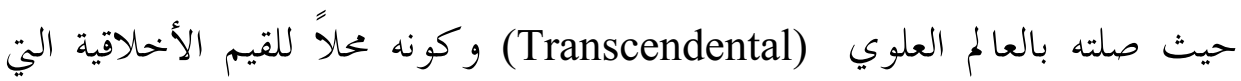

13 راجع تفصيل أوفن لهذه العلاقة، النجار، عبدالمحيد. "الإنسان و الكون في العقيدة الإسلامية"، مجلة المسلم المعاصر

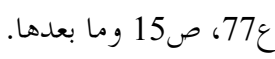

$$
14
$$

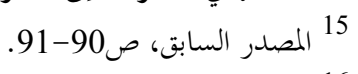

16 الــرازي، محمد بن عمر فخر الدين. كتاب النفس والروح، إسلام أباد: مطبوعات معهد الأبحاث الإسلامية، 
تفيض من خالق الوجود. أما فاعليته معرفياً فمن حيث صلته بالعالم المادي و كونه

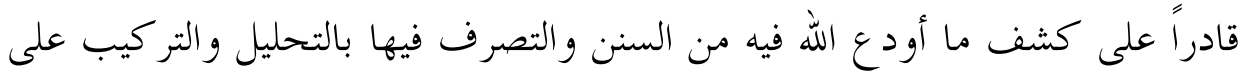

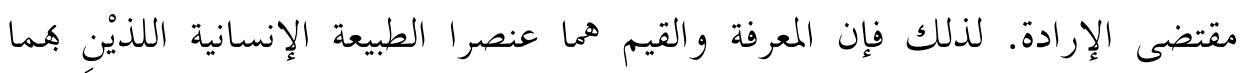

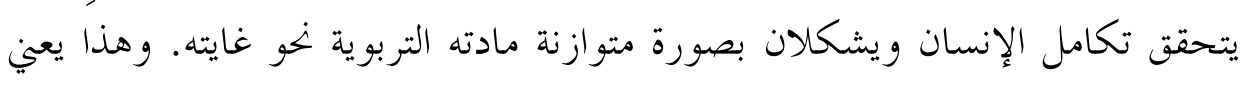

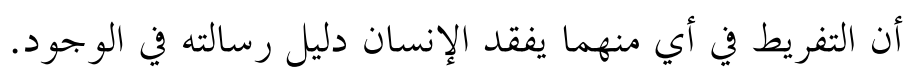

إن التفريط في الفاعلية يفقد الإنسان ما اختصّ به من فعل التعمير والخلافة وما

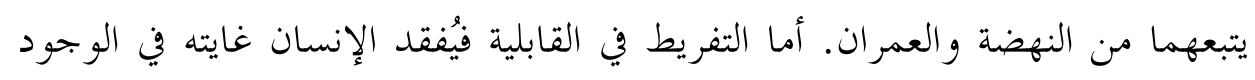

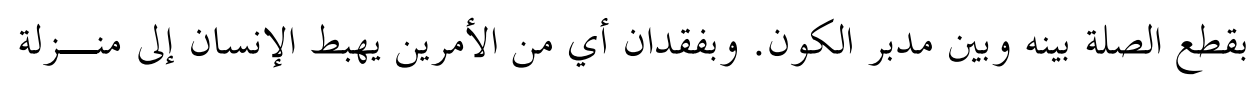

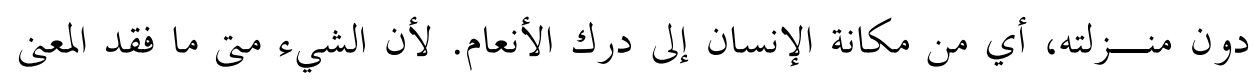

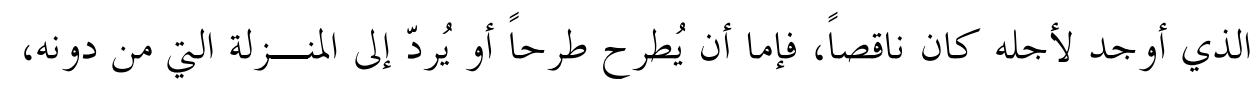

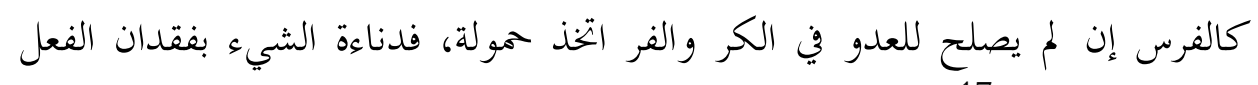
الذي صُنع لأجله.

هذه هي المعاني التي يجب أن تقصدها فلسفة التربية وتحتويها المادة التربوية في

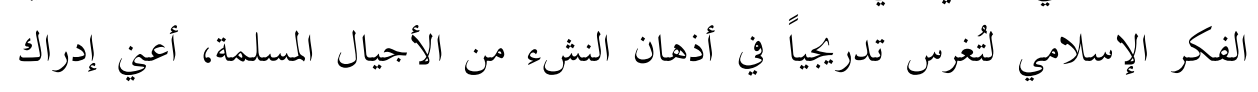
الإنسان غايته في الوجود ورسالته في الحياة وعلاقته .بما حوله من الخلائق.

أما طبيعة الإنسان في الإسلام من حيث ذاته فطبيعة خيرة في الأساس، وهو

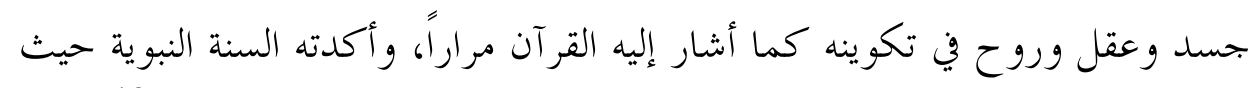

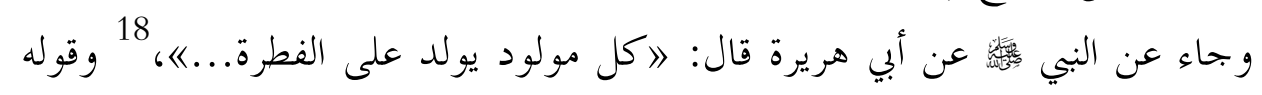

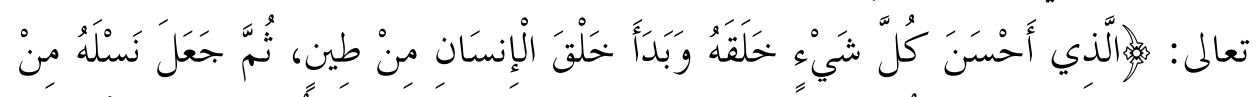

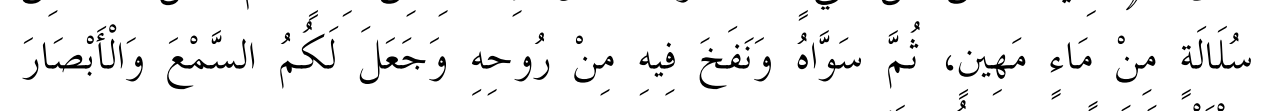

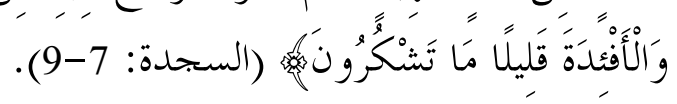

18 17 الأصفهاني. الذريعة إلى مكارم الشريعة، مصدر سابق، ص91.

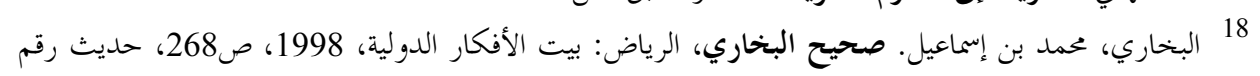




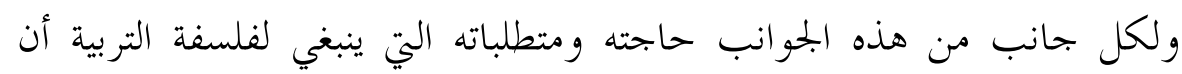

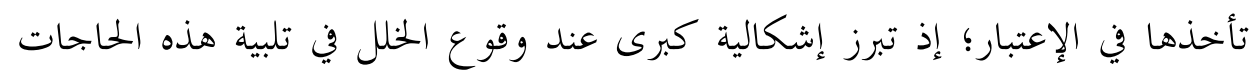

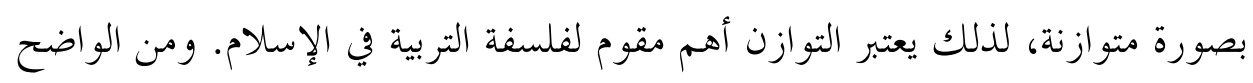

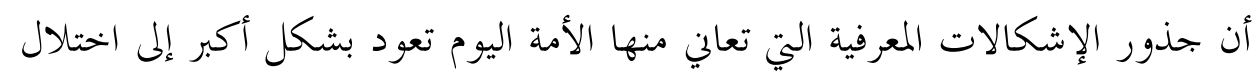
هذا التوازن في أكثر الأحوال.

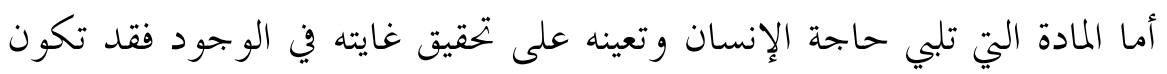

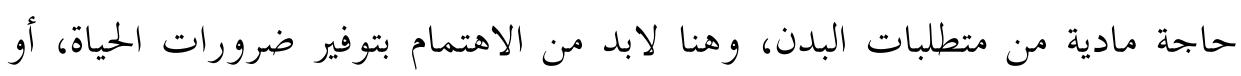

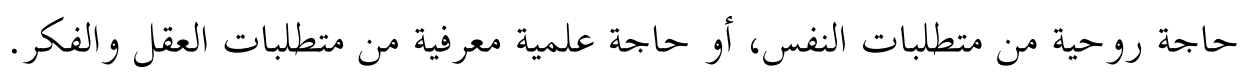

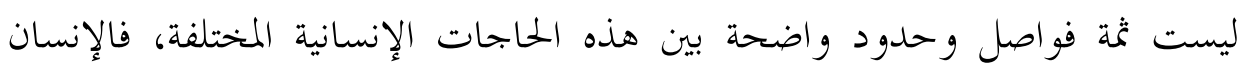

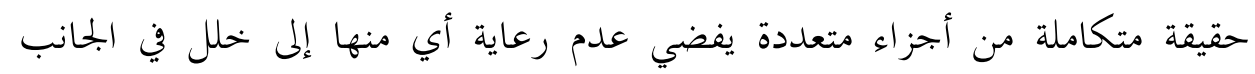

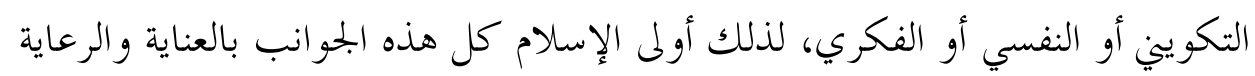
في توازن ونسق عجيب.

المقصود بالمنهج التربوي في الإسلام هو هذا النسق الذي يحقق التوازن في كيان

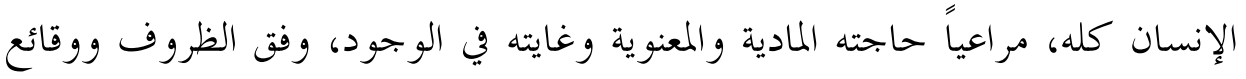

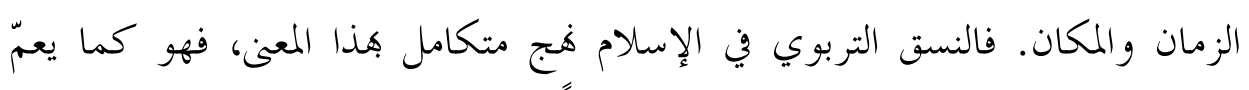

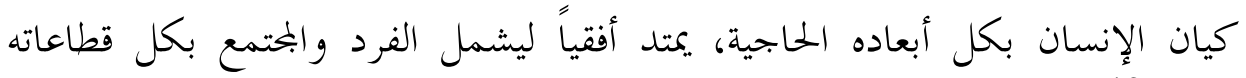
وفئاته. 19 وهي عملية لا تنتهي عند حلد، بل إنسان تستغرق عمر الإنسان كله كما أشار إليها الحديث النبوي الشريف.

من خلال هذا النسق يظهر التباين بين مفهوم "التعليم" الذي صار شائعاً في هذا

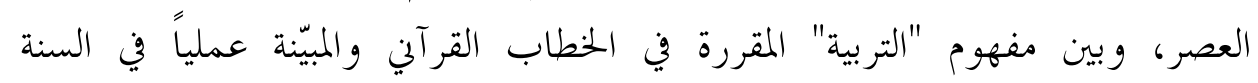
19 لأغــــاض التربية يضع بعض العلماء البحتمع في ثلاث طبقات: طبقة العامة من أهل الصناعة والتجارة والزراعة

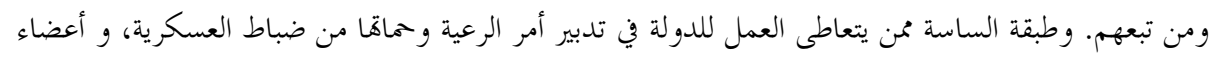

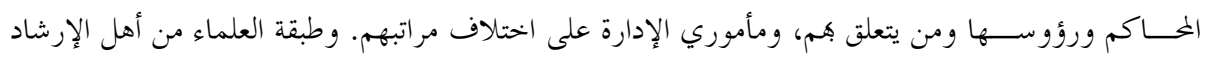

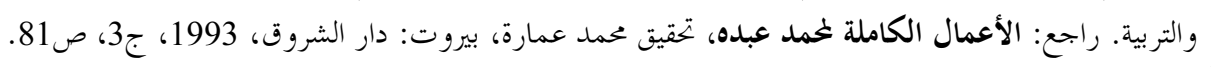
20 
النبوية. 21 إذ إن التعلّم إنما هو أداة من أدوات التربية في سبيل تحقيق الإنسان غايته في

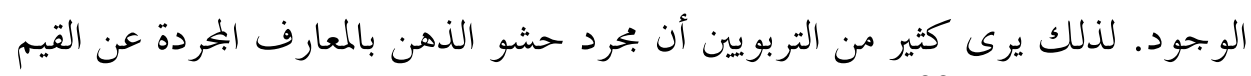

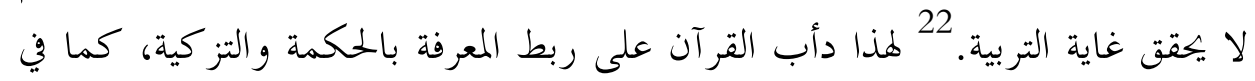

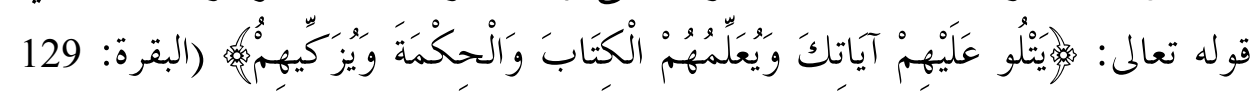

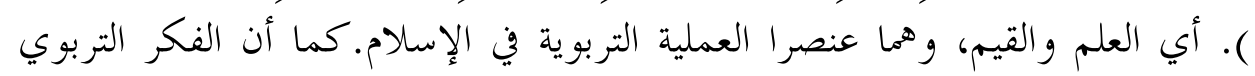

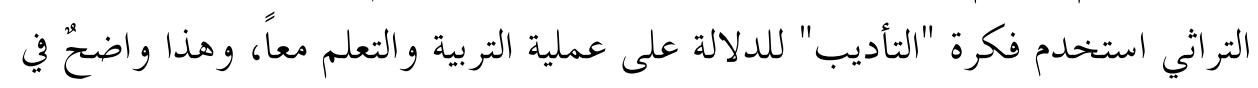
التراث الإسلامي من الناحية العملية الأمر الذي يدعونا إلى صياغته من الناحية النظرية بلغة العصر.

\section{ثالثاً: أزمة الفكر التربوي الإسلامي بين العقلية التحليلية والعقلية التفويضية}

إن التوازن الدقيق في النظام التربوي الإسلامي بين عنصريه المعرفي والقيمي قائم على وسطية الإسلام التي تنبذ التطرف بكل صوره وتنشد التوازن بكل خصائصه.

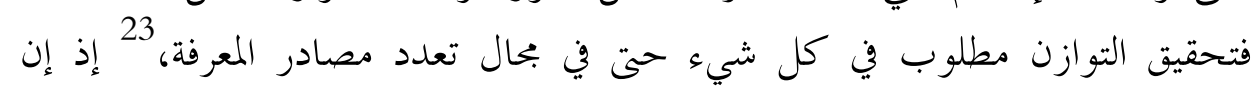

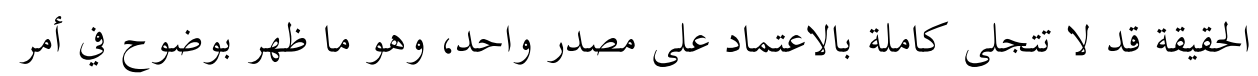

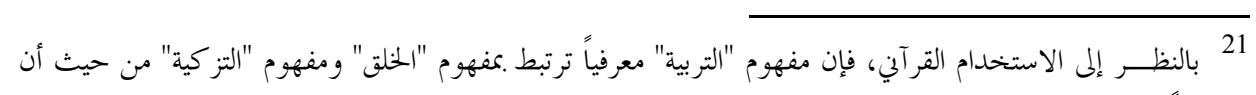

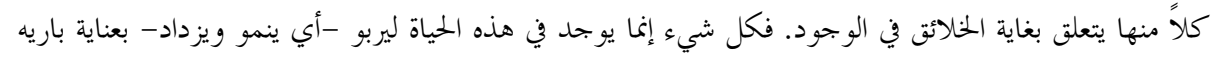

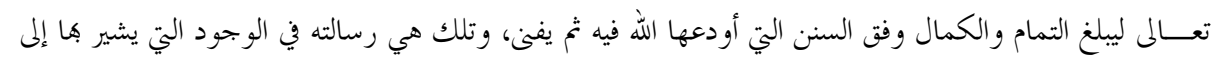

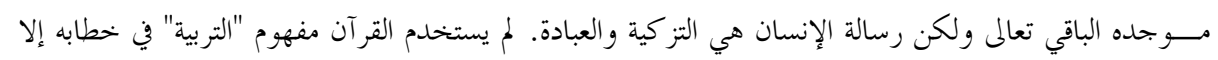

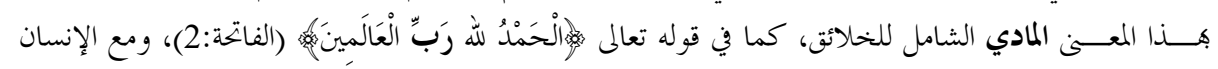

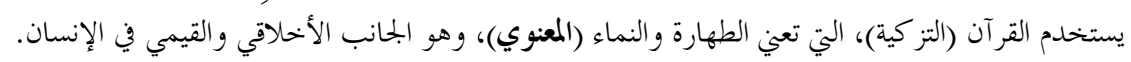

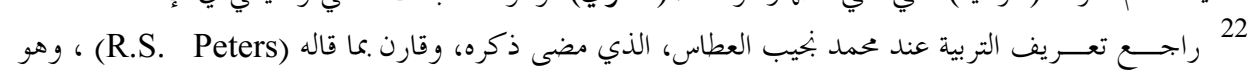
فيلسوف غربي:

(We do not call a person "educated" who has simply mastered a skill. For man to be educated it is insufficient that he should possess a mere know-how, he most have also some body of knowledge and some kind of conceptual scheme to raise this above the level of a collection of disjointed facts ), An Introduction to Philosophy of Education, Robin Barrow \& Ronald Woods (editors), Routledge (London 1994) P. 14 23 لمعــرفة المــزيد من خصائص التصور المعريف في الإسلام انظر، شوقار، إبراهيم. الإطار المعربي للسنن الإلهية في

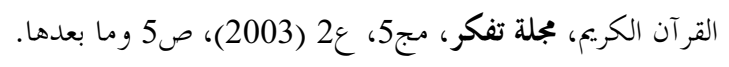




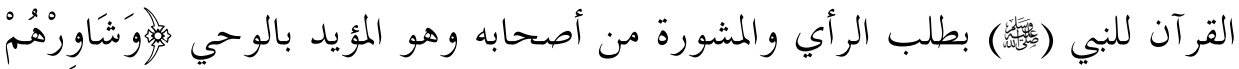

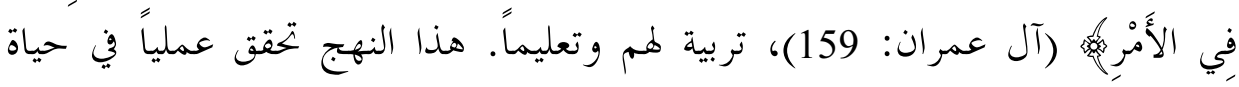
الصحابة وقام عليه الفكر الإسلامي كما ظهر في بعض المصطلحات مثل المات "المنقول

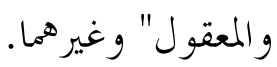

إن منهج الوسطية في الإسلام قد يتعرض لاختبار وفق صروف الزمان بان باختلال

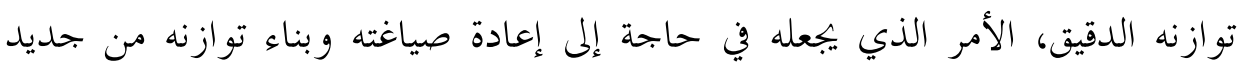
وفق المعطيات الظرفية، لكن لما غفل المسلمون عن هذا العنصر الاختباري المتغيّر في

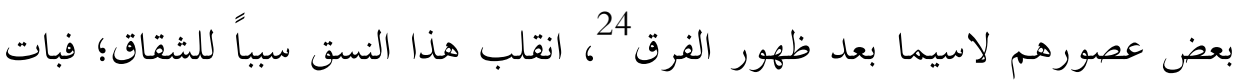

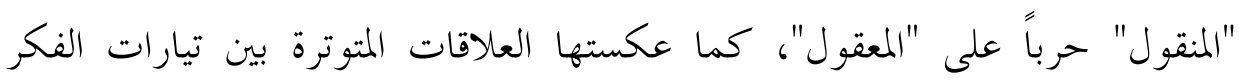

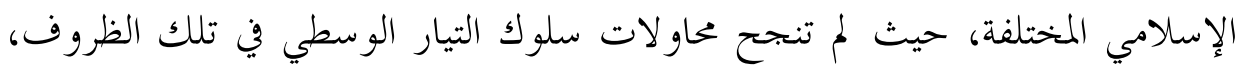

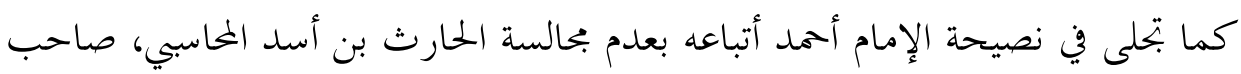

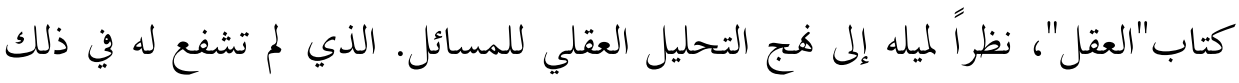

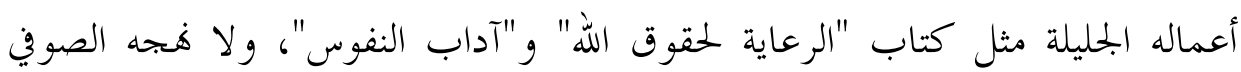
الصارم ومر اقبته الدقيقة للنفس حتى عُرف بالحاسبي على سبيل الرعايل المثال.

إن عزل المعقول عن المنقول، اللذان هما عنصرا النسق التربوي المعريف والقيمي

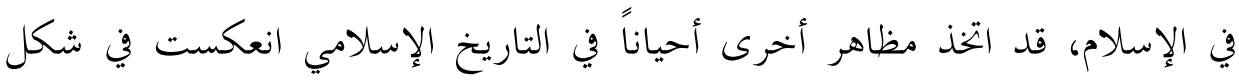

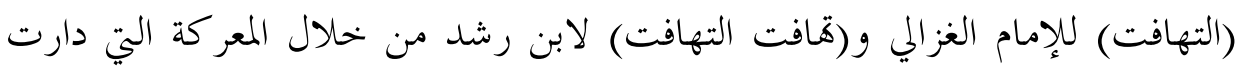

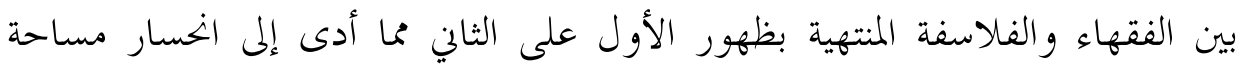

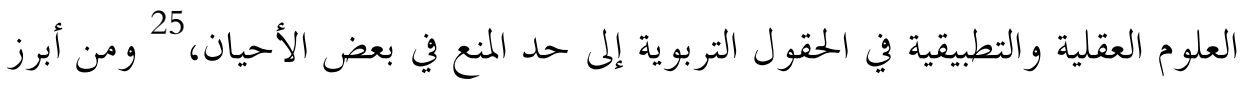

24 كـــان ظهور الفرق المتقاتلة في الإسلام انعكاساً لاختلال النظرة الكلية، وذكرنا فيما سبق أن لأي اختلال في

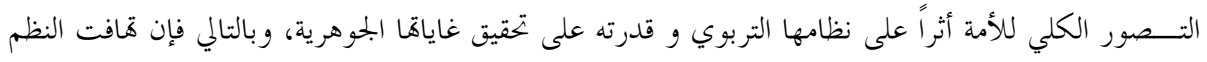
التربوية قد تقتضي إعادة النظر في فلسفتها الكلية.

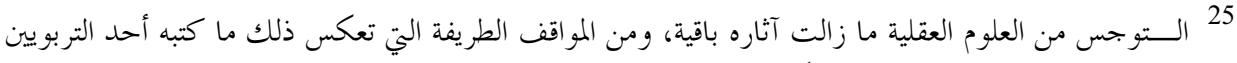

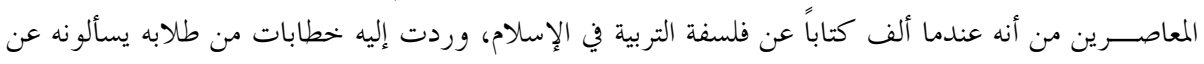

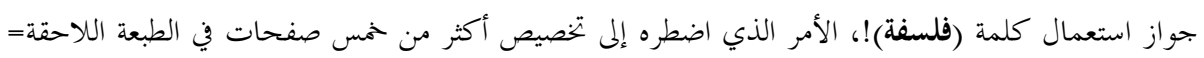


تبعات هذه العملية فقدان فعل التعمير وهو ما أشار إليه الرازي بـــاعلية الإنسان في

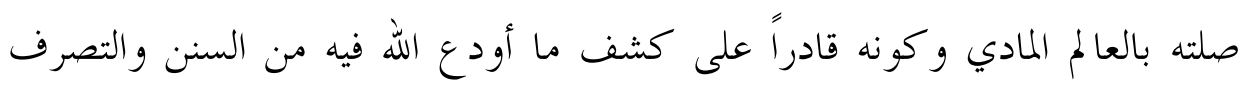
فيها بالتحليل والتر كيب على مقتضى الإرادة".

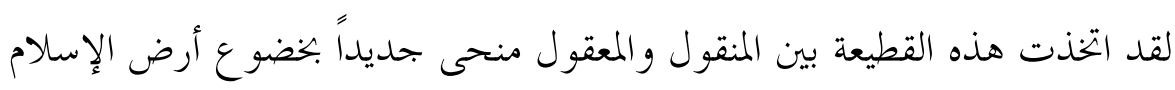

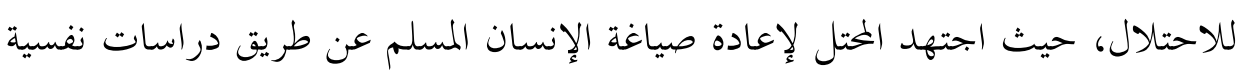

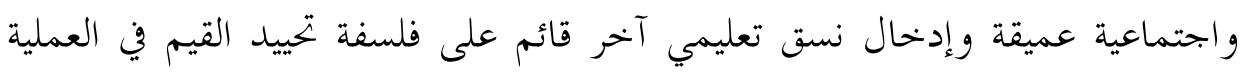

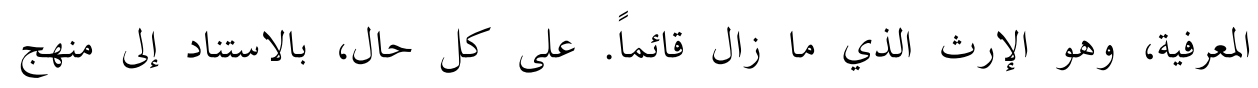

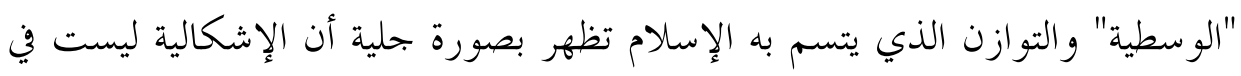

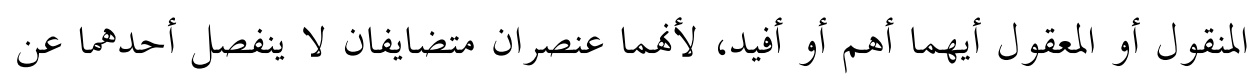

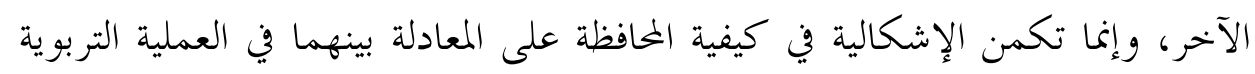
في ظل أوضاع دولية متغيرة في غاية التعقيد.

\section{رابعاً: محاولات التوفيق}

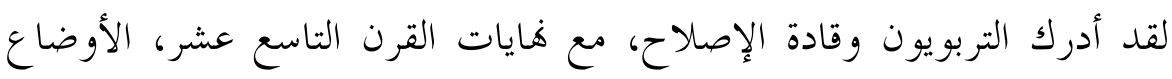

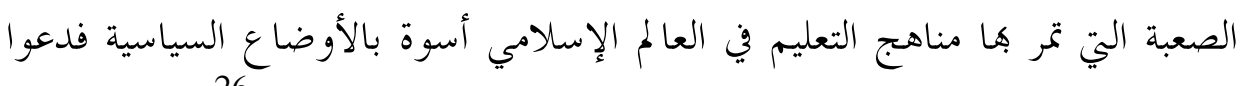

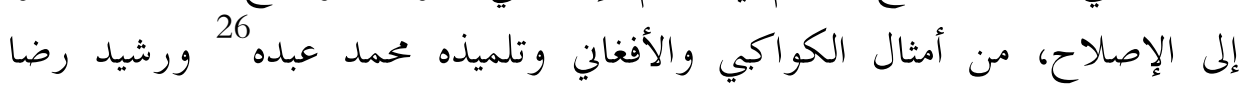

=لتبرير استخدامه لذذا المصطلح !. رابع الكيلاني، ماجد عرسان. فلسفة التربية الإسلامية، بيروت: مؤسسة

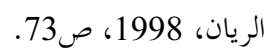

26 كستب عمـــد عبده عن الأسباب الفكرية لاغططاط المسلمين في عصره فقال: (وإذا استقرينا أحوال المسلمين

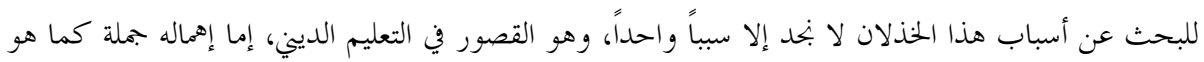

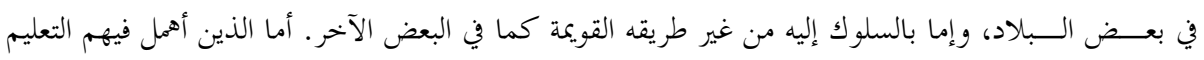

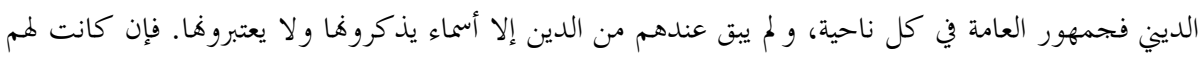

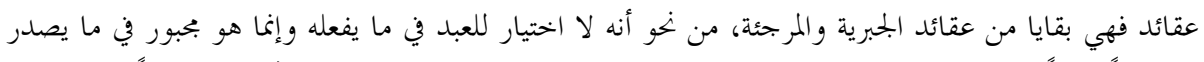

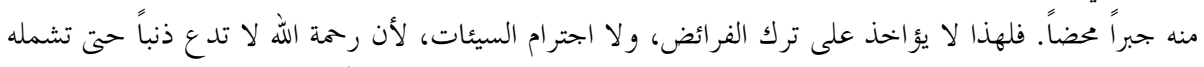

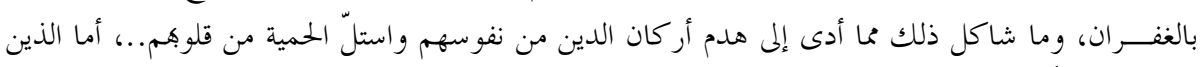

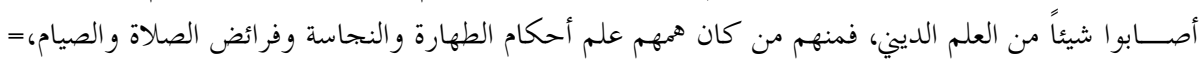




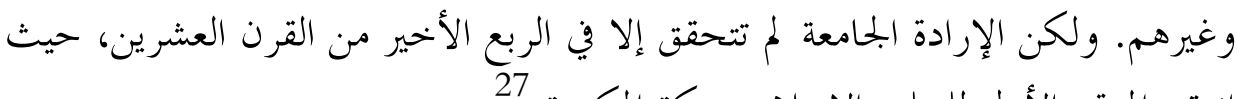
انعقد المؤتمر الأول للتعليم الإسلامي بمكة المكرمة.

حاول المؤتمرون إيياد تصور عن أولويات البناء التربوي وإيجاد صيغة توافقية بين

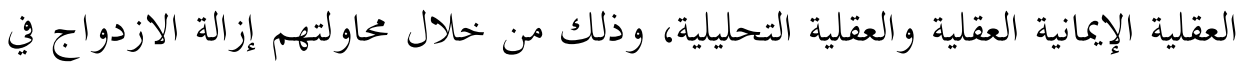

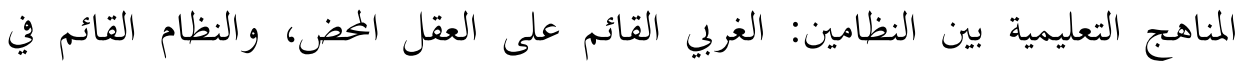
التعامل مع التراث على النقل البحرد. وتمثلت أهداف المؤتمر في ثلاثة أمور:

1 - تحديد المبادئ الأساسية والمقاصد العامة والمفاهيم الشاملة للتعليم الإسلامي. 2 - الوصول إلى هج واضح متكامل وطرائق مثلى لتطبيق المبادئ وبلوغ الأهداف. 3 - تعقيق التعاون بين العاملين في الحقل التعليمي وتعميق الوعي بينهم وتوحيد وجهات النظر في الأهداف والوسائل التعليمية.

وقد برزت محاولة المؤتمر لترميم الهوة بين المنقول والمعقول من خلال إعادة تعر يفه لغاية التعليم ومفهوم العبادة؛ إذ جاء في مقر راته أن "هدف التهات التعليم الإسلامي هو

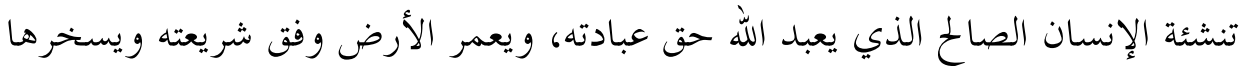

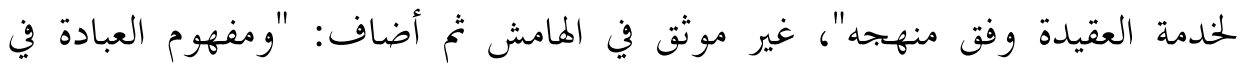

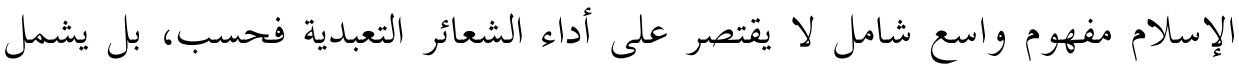
نشاط الإنسان كله من اعتقاد وفكر وشعور وتصور وعمل، مادام الإنسان يتوجه هئل الإنا النشاط إلى الله ويلتزم شرعه وسار على منهجهه".

و بناء على هذين التعريفين، أعني غاية التعليم ومفهوم العبادة، تقرر مفهوم التربية

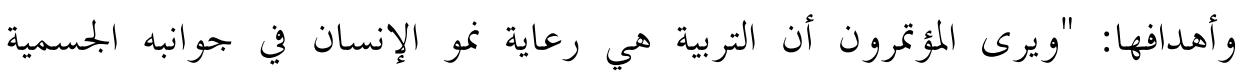

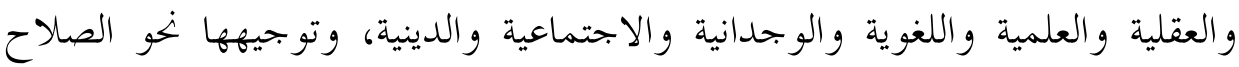

= وظظوا أن الدين منحصر في ذلكا، ويشتركون مع الأولين في تلك العقائد الفاسدة). رابع: الأعمال الكاملة

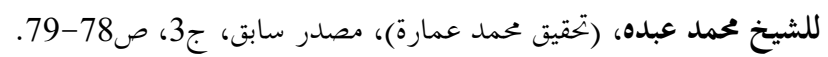

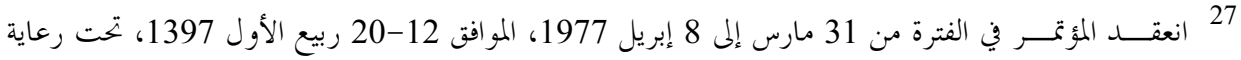

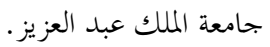


والوصول ها إلى الكمال. و الغاية من التربية هي تحقيق العبودية الخالصة لله في حياة

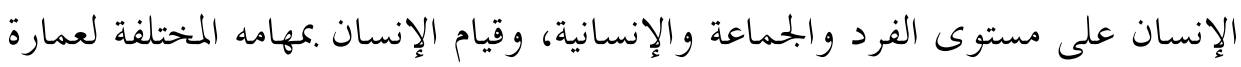
الكون وفق الشريعة الإلهية."28

وعلى ضوء غاية التربية تم تصنيف المعارف إلى نوعين: الأول هو: المعرفة القائمة

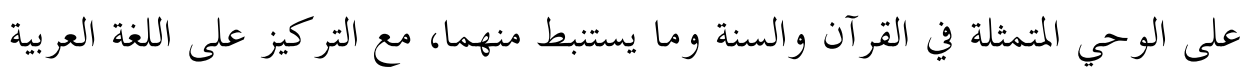

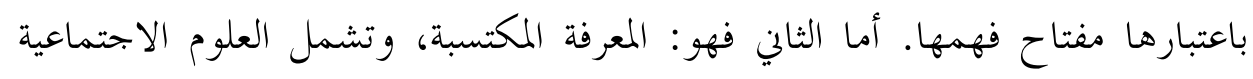

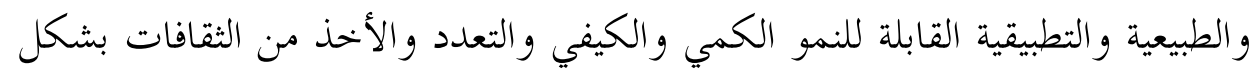
يحافظ على انسجامها مع الشريعة كمصدر للقيم.

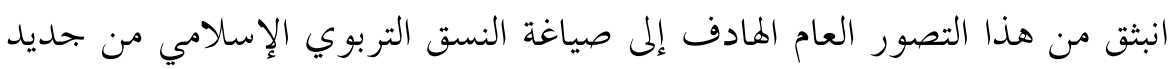

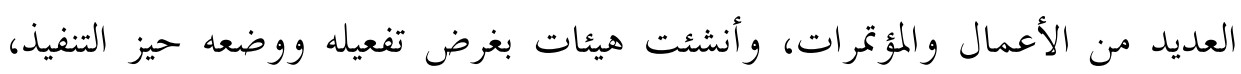

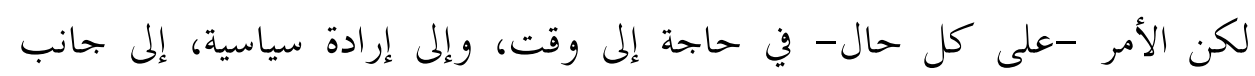

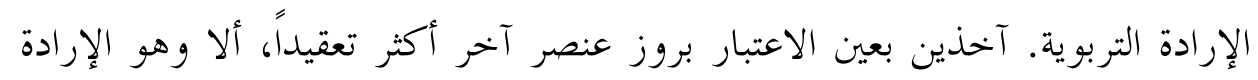

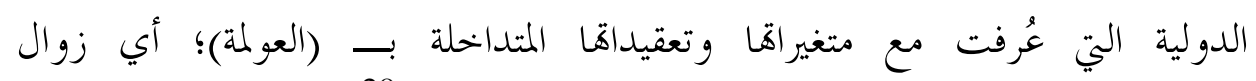
الخصوصيات في كثير من الشؤون في حياة الأمم والشعوب. 29

\section{خامساً: مقومات فلسفة التربية في عصر العولمة وعالم المتغيرات}

من أجل بناء نسق تربوي متكامل، بعنصريه المعرفي والقيمي، في هذا العصر

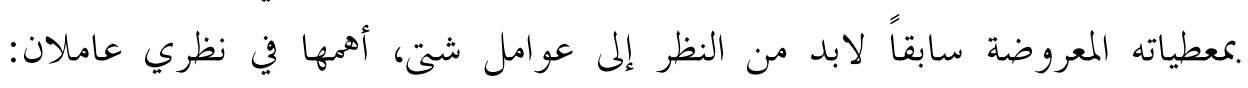

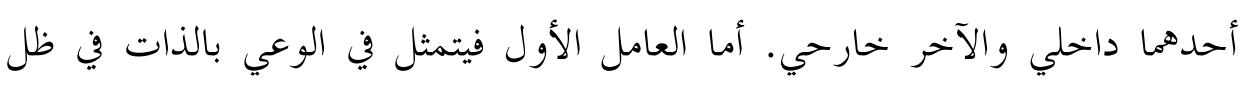

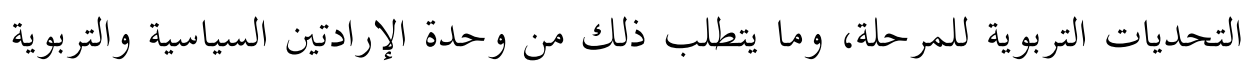

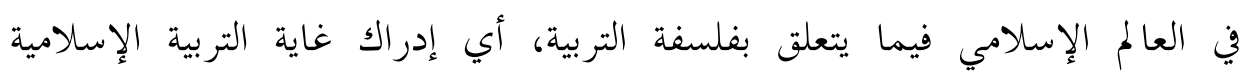

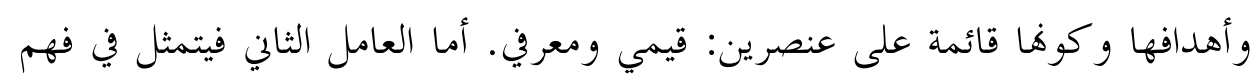

$$
\text { 28 }
$$

29 شوقار، إبراهيم. "العولمة والعالمية في ضوء سنن الله الكونية"، مصدر سابق، ص142 وما بعدها. 
طبيعة العصر والإدراك الجيد لظروف الواقع الدولي هيمنته وطغيانه المادي، وتداخل

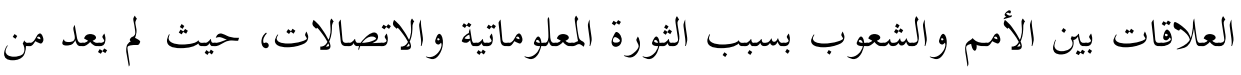

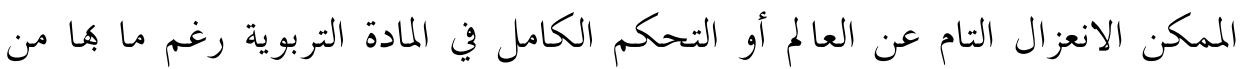
شوائب ومخاطر على النشء والأسرة ووسائل التربية بصورة عامة. إن خير وسيلة لتحقيق غاية التربية الإسلامية، في ظل هذه المعطيات، هي العمل

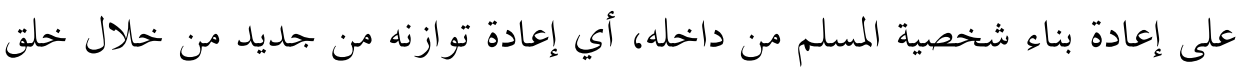
حالة التمنع و القدرة على الاحتكاك بالآخر. و ويتحقق هذا التوازن - في نظرنا- بإعادة غرس المعاني الكلية للتصور الإسلامي، مثل علاقة الإنسان بالوجود، في النفوس بأسلوب يواكب العصر، ليتحدد بذلك بعض المفاهيم الإسلامية مثل مفهوم "الإنسان

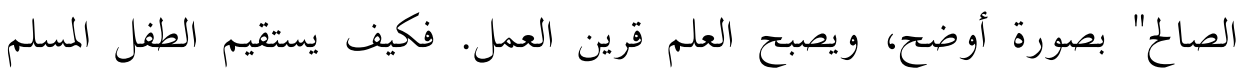

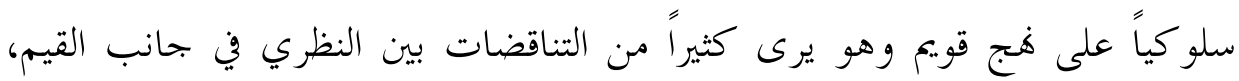
والسلوك الو اقعي التطبيقي في البحتمع المسلم. من هنا تأتي حتمية التأسيس لفلسفة التربية الرشيدة تنبين على قيم الدين وقواعد

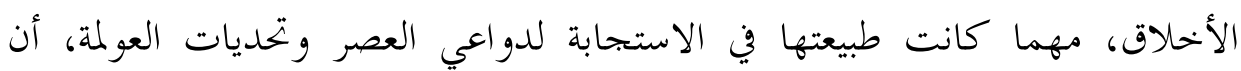
تسترشد بالمقومات التالية:

\section{1. مقومات فلسفة التربية من منظور عقدي فكري}

إن أهم مقوم لفلسفة التربية من منظور عقدي كوها منبثقة عن الرؤية الإسلامية

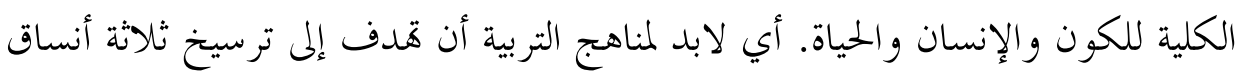
من العلاقة بين الإنسان والوجود من حوله في أذهان النشء؛ الأولى: علاقة الإنسان بخالقه وهي علاقة عبودية؛ واستخلاف وطاعة. والثانية: علاقة الإنسان بالكون و الحياة. و هي علاقة تسخير وعطاء، أي بناء وتعمير وإعداد لحياة أخرى أفضل ولكن تُجنَى ثمرها

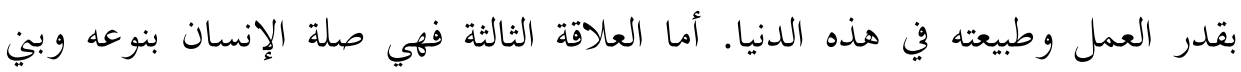
جنسه؛ وهي علاقة أخوة إما في الدين أو النسب أو الإنسانية، قائمة على الحق، و العدل 
والمساواة ورعاية العهد والتعاون على البر والتقوى. هكذا يجب أن تتم صياغة المناهج

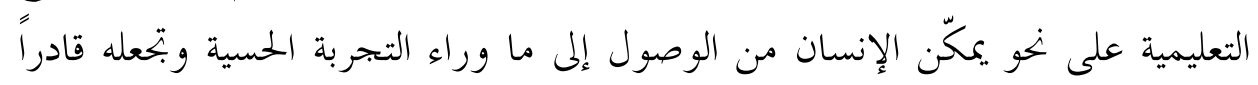
على التفكير بطريقة شمولية في الكون وما فيه من قدرة إلهية مبدعة. ومن مقومات فلسفة التربية من منظور فكري ضرورة التنمية العقلية لتكون

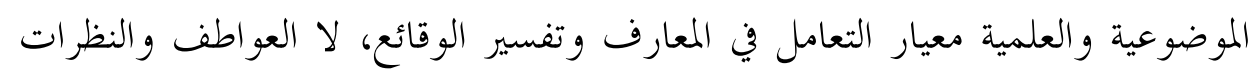

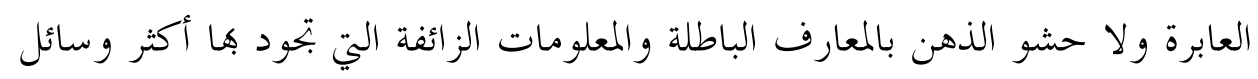

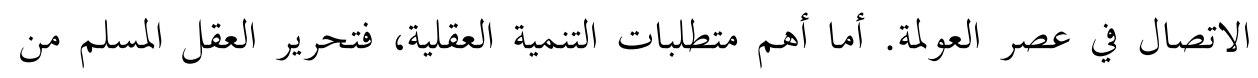

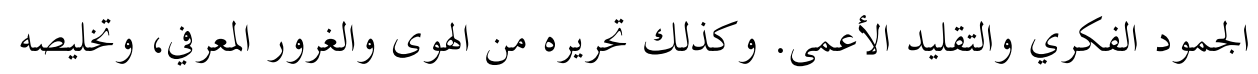

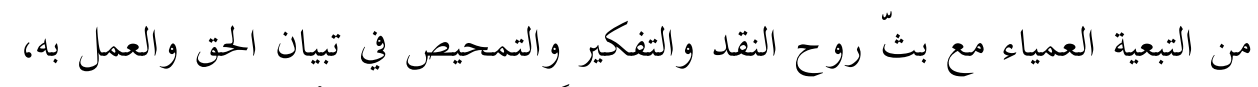

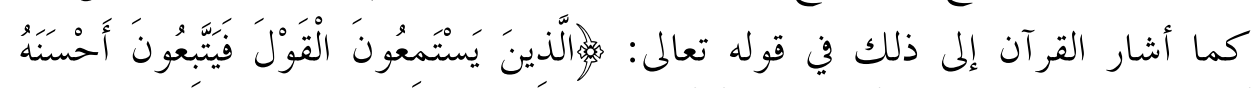

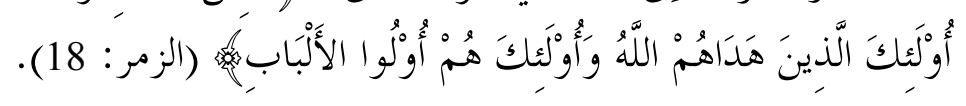

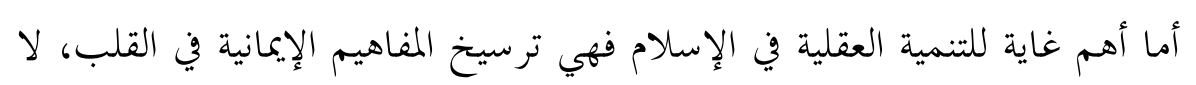

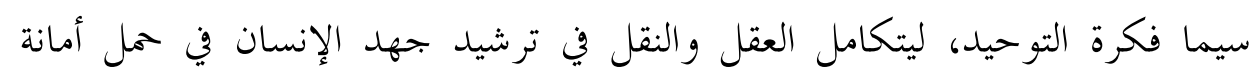

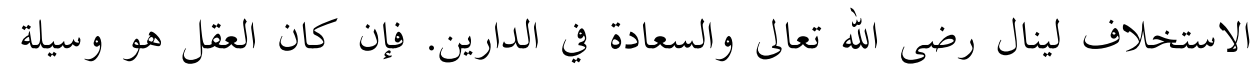

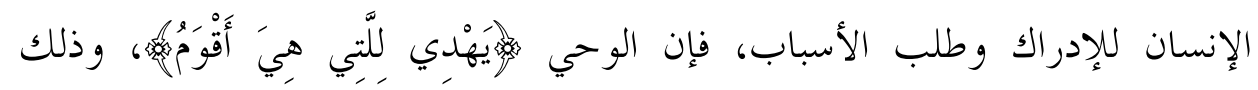

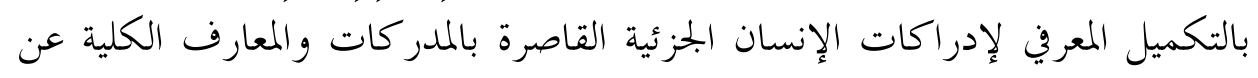

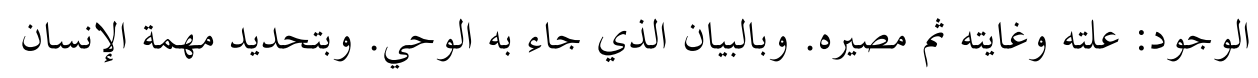

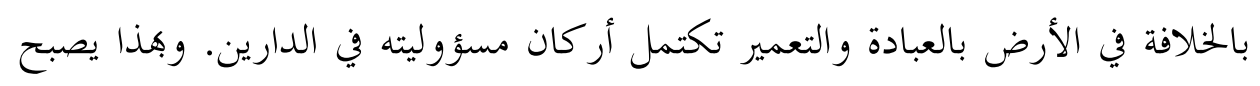

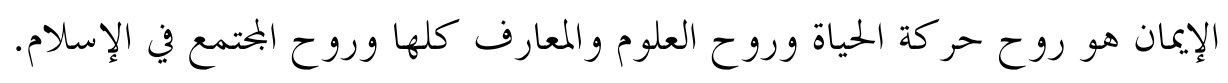

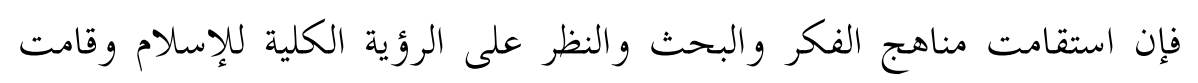

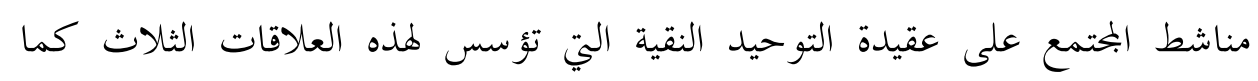

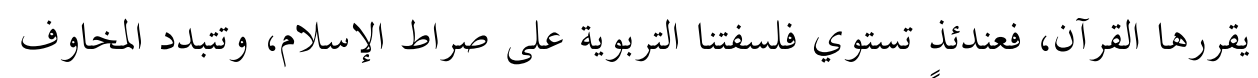

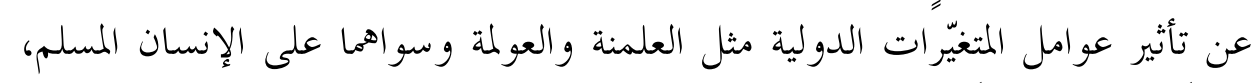
ناشئاً كان أم راشداً. 


\section{2. مقومات فلسفة التربية من منظور أخلاقي قيمي}

من أهم مقومات فلسفة التربية من منظور أخلاقي في هذا العصر كوها قائمة على

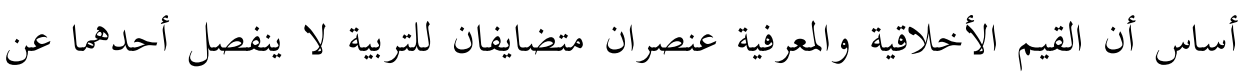

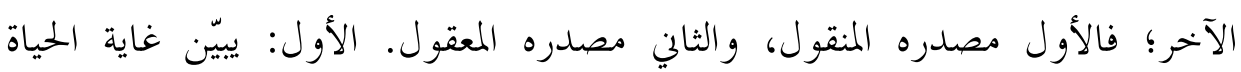
ومقاصدها، و الثاني: و سيلة لتحقيق تلك الغاية. لذلك ما يصيب أحدهما يؤثر في الآخر؛ فالحلل في الإيمان يترك الوسائل بلا هدف، والحخلل في العلم يترك الإيمان بلا و سائل. 30 و بناء على ذلك فإن لعنصر القيم الأخلاقية في الإسلام وظيفتين مع المعرفة؛ الأولى: تعمد إلى ضبط النمو المعرفي من الانحراف، سواء أكان عن المنهج العلمي

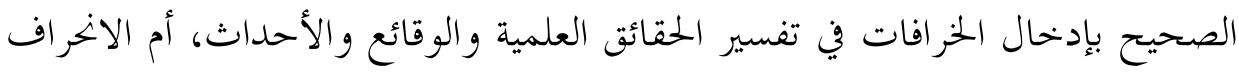

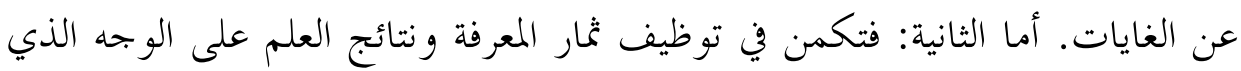
يجقق غاية الاستخلاف الإنساني في الوجود، لا التدمير أو الفساد في الأرض. ومن هذا الوجه، ينبغي للمناهج التربوية أن تستثمر علاقة المعرفة بالقيم بضرورة

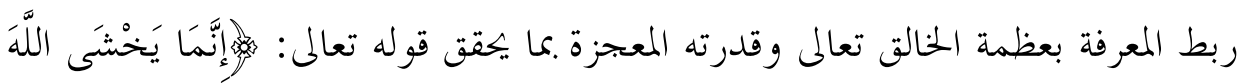

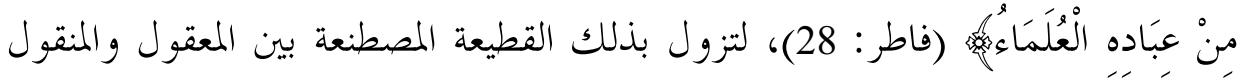

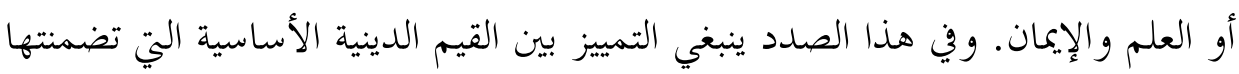

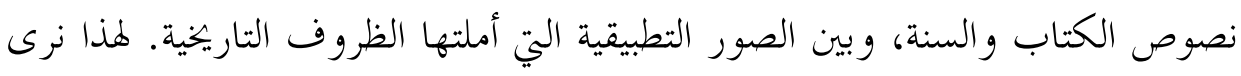
أن أهم مقوم لفلسفة التربية من منظور أخلاقي هو التمسك بقيم وحي السماء وسنن الفطرة السوية و بناء المناهج التربوية عليها، مهما كانت مغريات العصر وتحدياته.

\section{3. مقومات فلسفة التربية من منظور علمي معرفي}

من أهم مقومات فلسفة التربية من منظور معرفي كوفا مؤسسة على اتخاذ العلم مطية إلى الإيمان، كما هو وسيلة للوصول إلى حقائق التسخير في توظيف موجودات

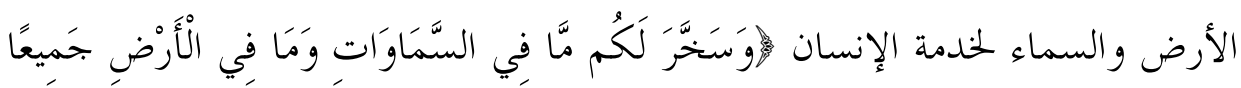


مثّنهُ (الجاثية: 13). فإذا كان طلب العلم فريضة في الإسلام فإن غايته هي معرفة

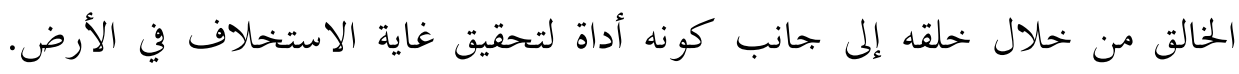

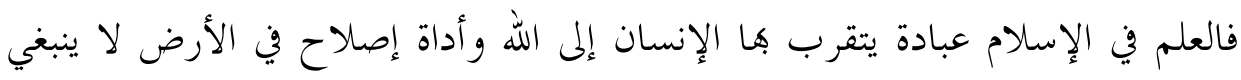

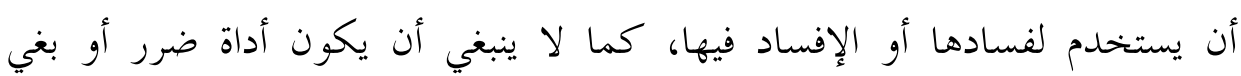

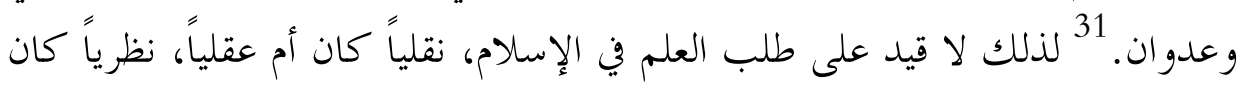

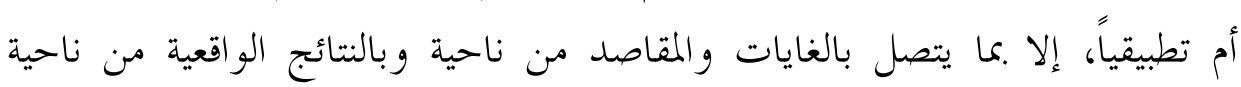

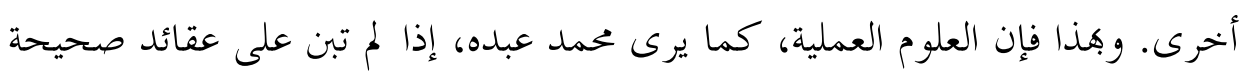

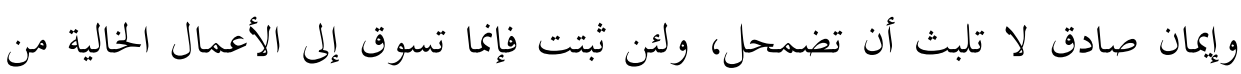

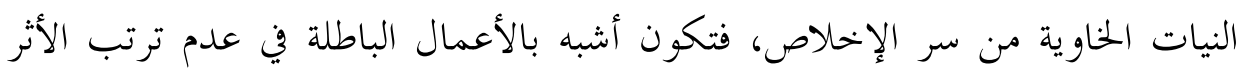
المطلوب منها.

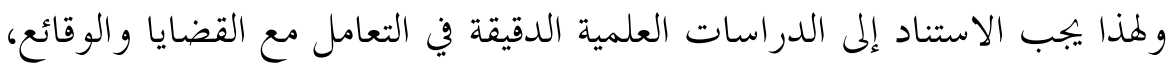

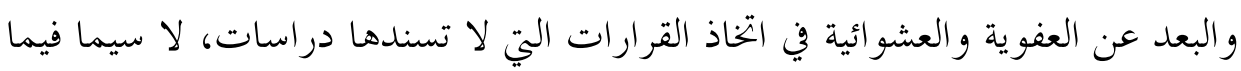

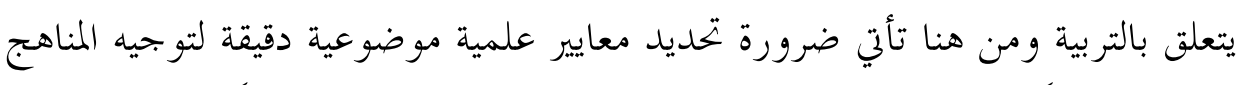

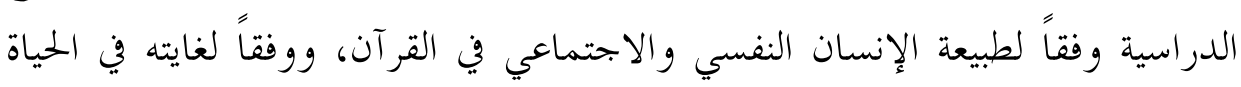
ورسالته في الوجود.

31 كانــت هذه النقطة من أهم النقاط التي تم تركيز عليها في مقر رات المؤتمر العلمي الأول للتعليم الإسلامي بمكة المكرمة عام 1977.

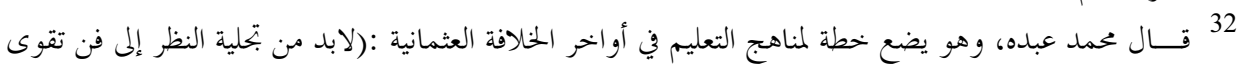

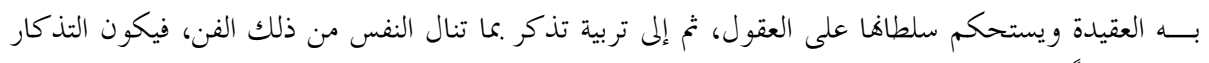

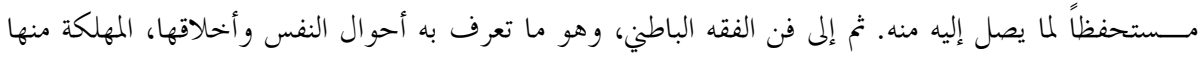

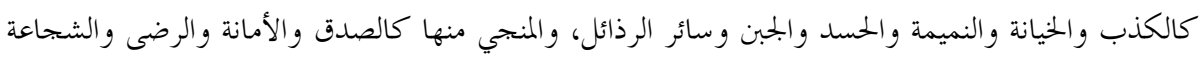

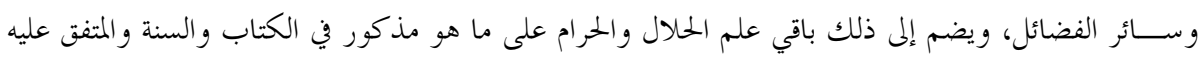

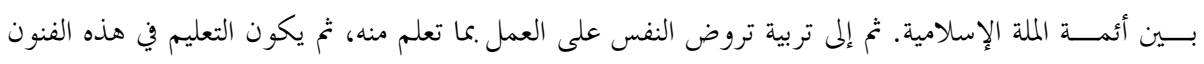

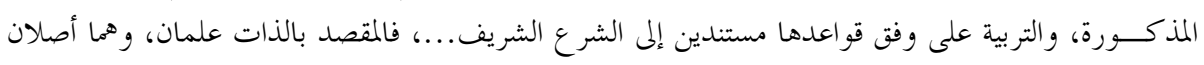

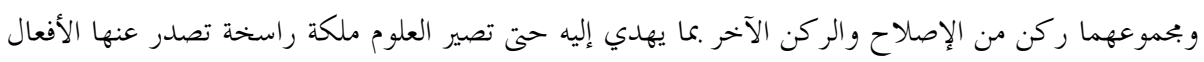

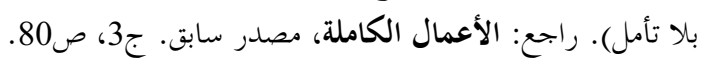


ويمكن تصنيف هذه المعايير العلمية إلى معايير موضوعية تعود إلى طبيعة المعرفة، ومعايير ذاتية تعود إلى طبيعة المتعلم، من حيث سنه وقدرته الاستعابية أو حاجة البحتمع الملحة، وغير ذلك. أما المعايير الدينية الأخلاقية فيجب أن تكون معايير مشمولة في سائر المعايير الأخرى بحيث تسري روحها الدينامية في كل العلوم. وبذلك يتم توحيد الرؤية بين المعارف الدينية الكونية المقتبسة من الوحي الإلهي، والمعارف الطبيعية والإنسانية المستخلصة من التجربة الإنسانية في كل بحالاتها عبر الزمان والمكان، لتحصل بذلك التهبك النقلة المنهجية المطلوبة ويتم الدمج والتكامل بين المعارف وينضبط العلم بالشريعة والأخلاق.

\section{4. مقومات فلسفة التربية من منظور اجتماعي}

وفيه نرى أنه لا يمكن القيام بمهمة الاستخلاف مالم يكن المستخلَف واعياً بالبعد الاجتماعي لفلسفة التربية. أي الوعي بالغير أسوة بالوعي بالنفس، الأمر الذي يقتضي بناء مناهجنا التربوية على دراسات دقيقة في علمي النفس والاجتماع. لأنه من المعلوم أن العملية التربوية لها جانبان لا يمكن إهمال أي منهما أو اختزاله في الآخر؛ الجحانب

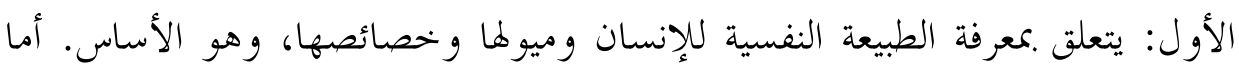
الجانب الثاني: فيتعلق بمعرفة البحتمع من حيث كون الإنسان كائن اجتماعي لابد له من محيط اجتماعي يعيش فيه وبيئة اجتماعية تحيطه بالرعاية والعناية، يتأثر هـا ويؤثر فيها. لذلك لابد من معرفة الظروف الاجتماعية والحضارية التي يعيش فيها الإنسان من أجل الإدراك الصحيح لميوله وقواه مقارنة بو اقع المختمع وظروفه إلى جانب غاية الإنسان في الحياة. ومن غير رعاية هذين الجحانبين فإن العملية التربوية ستكون أشبه بعشوائية أو أو إس تحكمية، وفيما يتعلق بالجانب الأول، أي معرفة الطبيعة النفسية، يجب أبن أن يكون التصور

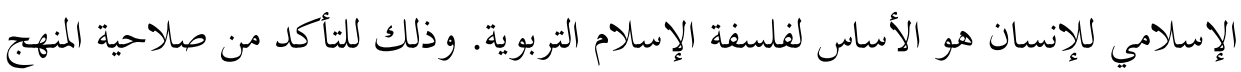
وملاءمته في صياغة الإنسان الرسالي في بحتمع العولمة والثقافات المتداخلة.

إن القرآن قد بيّن بصورة دقيقة التكوين النفسي للبشرية؛ إذ إن الإنسان هو

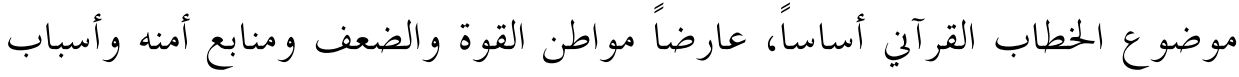




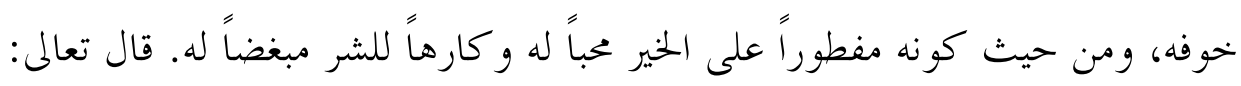

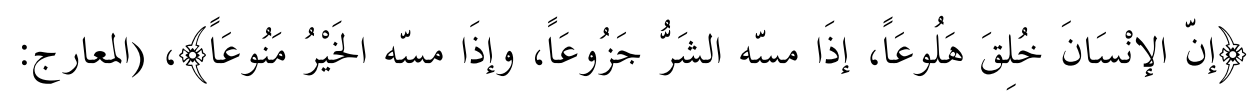

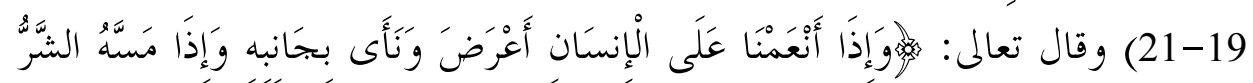

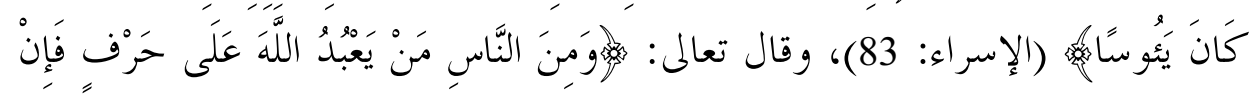

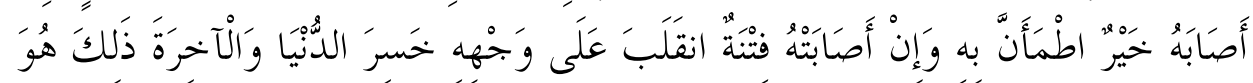

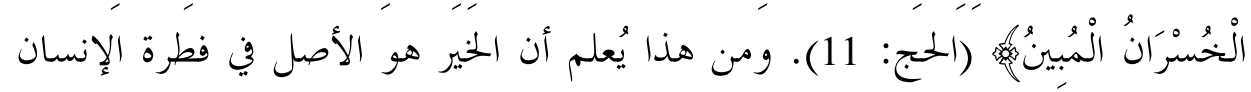

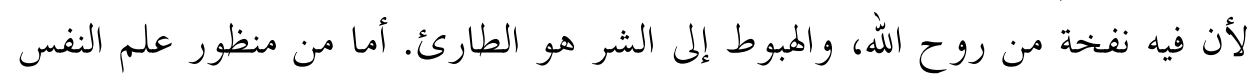

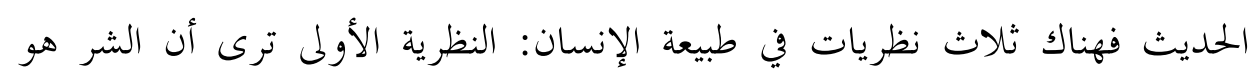

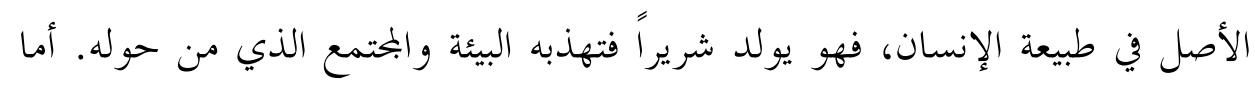

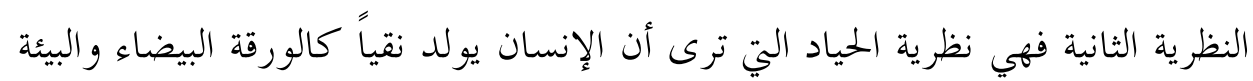

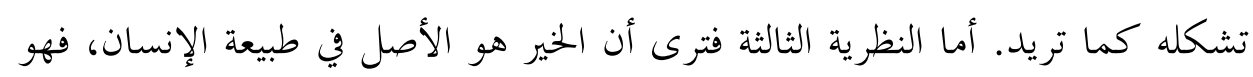

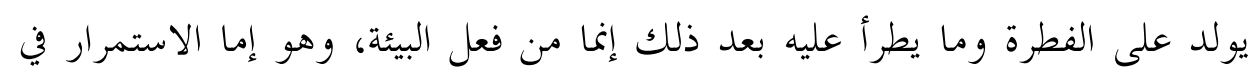

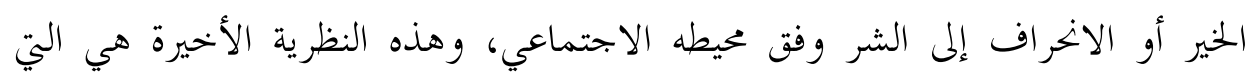
33

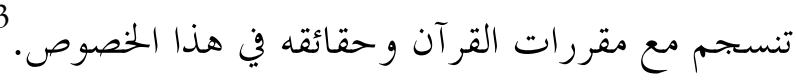

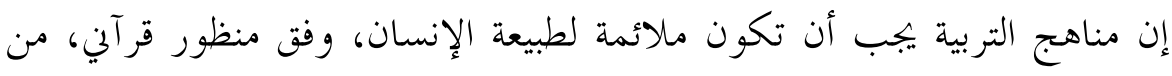

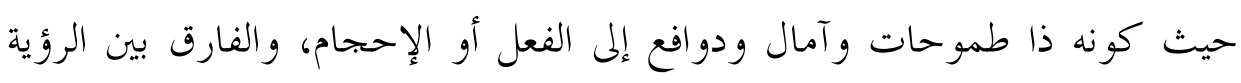

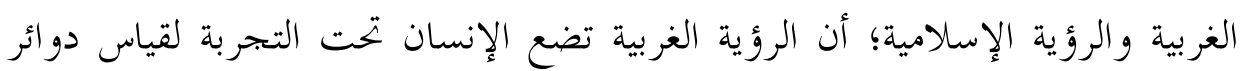

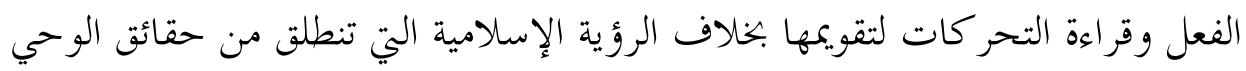

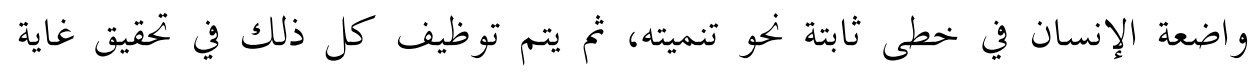

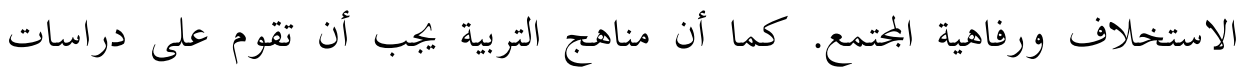

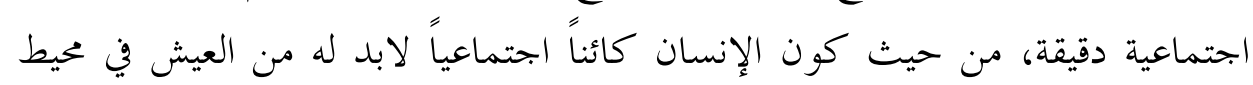

333

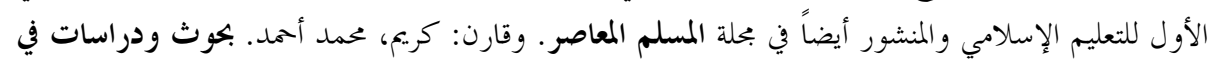

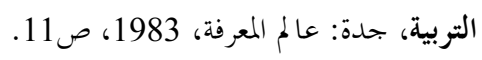


اجتماعي يتأثر به ويؤثر فيه، ولا سيما في هذا العصر الذي اقتربت فيه المسافات بين الأمم وتداخلت الثقافات بفعل ثورة الاتصالات وسهولة الحركة. فلابد من تربية

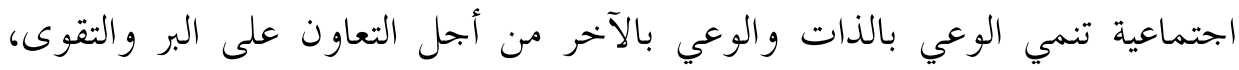

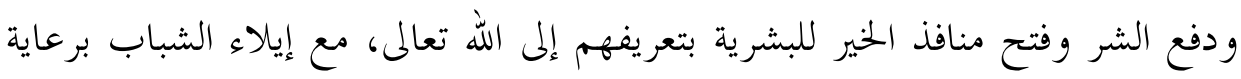

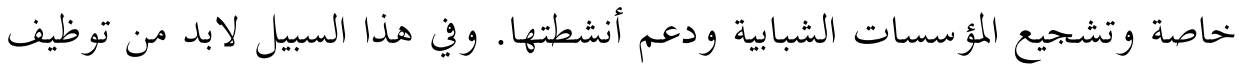
ثورة الاتصالات ووسائل الإعلام وترشيدها بما يخدم غاية المناهج التربوية في سعيها لإيجاد الإنسان الرسالي الذي يحمل قيم السماء ورسالة الاستخلاف، وروح البناء الحضاري والطمع في رفاهية المختمع في الدنيا والنعيم المقيم في الآخرة..إنسان جامع بين المنقول و المعقول، أو القيمي و المعرفي من جهة نظم خطابه وتهنيه وتنية اتصاله.

\section{الحناتمة}

إن هذه الدراسة التحليلية في مقومات الفكر التربوي في الإسلام تُظهر بجلاء أن

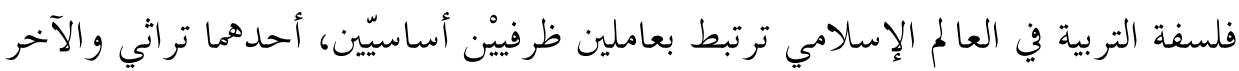
آني متغير:

فالعامل التراثي يرتبط بالتصور المعرفي الكلي (Epistemology)، الذي تضرر

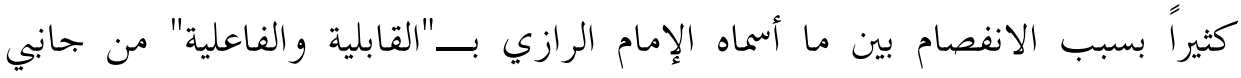
شخصية الإنسان المسلم، فوقع انفصال المنقول عن المعقول من عناصر الوجيه في

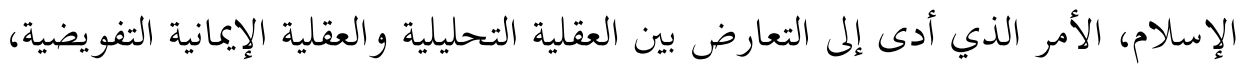

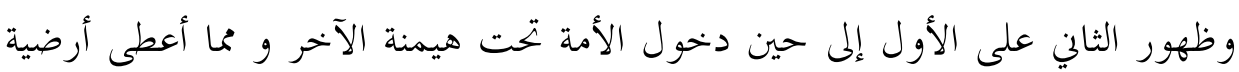
في ظهور العلمنة وجدليات فصل الدين عن الحياة.

أما العامل الآني المتغير فيرتبط بالواقع الدولي المتغير؛ إذ إن فلسفة التربية تتأثر كمحيطها الاجتماعي، كما تتأثر بتصورها الكلي. وقد ظهر دور هذا العامل جلياً عندما

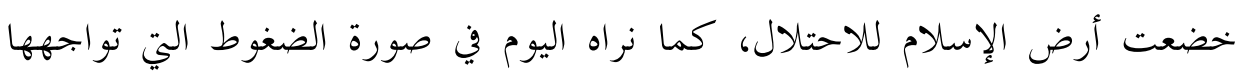
الأمة في أمر مناهجها التربوية. 
في نظري، إن دور هذا العامل ليس كبيراً، وإنما يظهر بقدر ضعف العامل الأول.

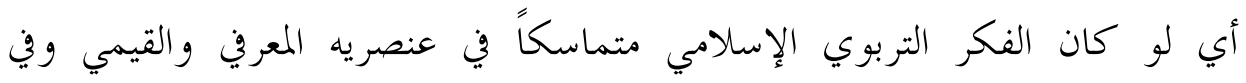

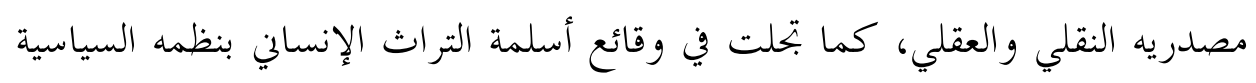

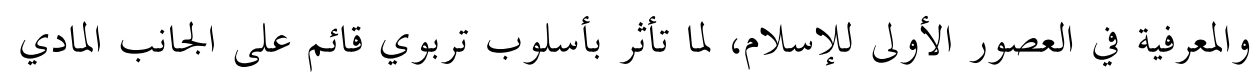

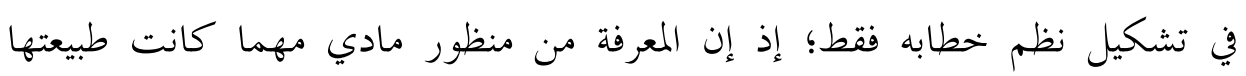

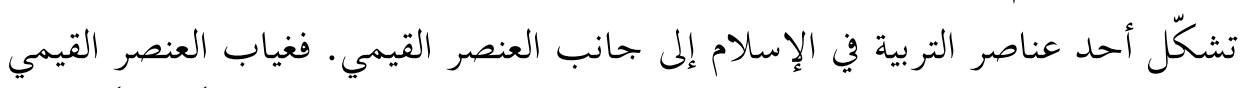

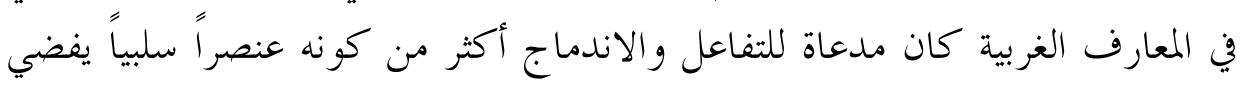

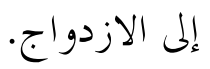

من هذا المنطلق نرى أن مشروع (أسلمة العلوم والمناهج) يجب أن ينصرف بشكل

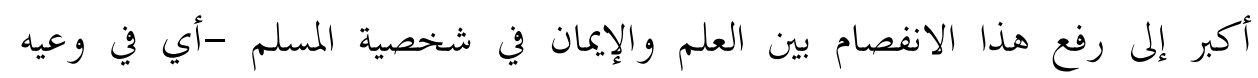

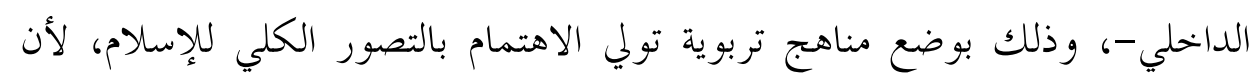

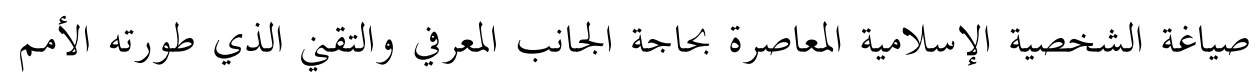

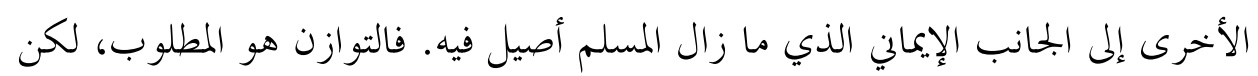

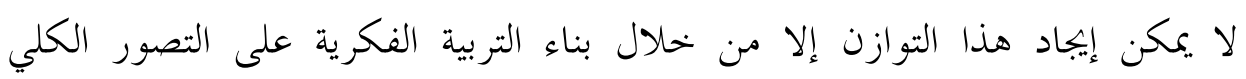

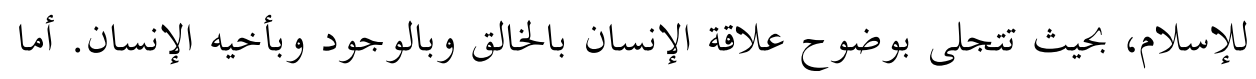

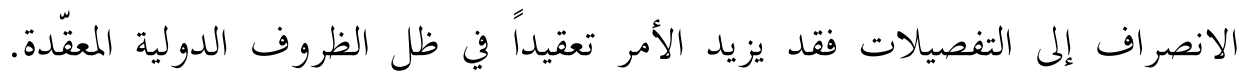

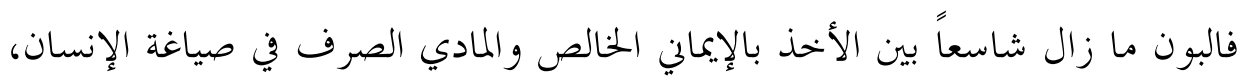

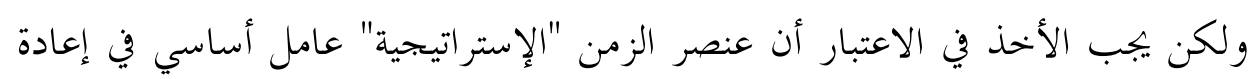
صياغة الأمم، إذ لا يتم ذلك بين عشية وضحاها.

مع غرس معاني التصور الإسلامي لإعادة بناء شخصية المسلم الحامل لرسالة

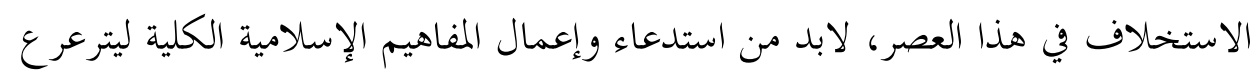

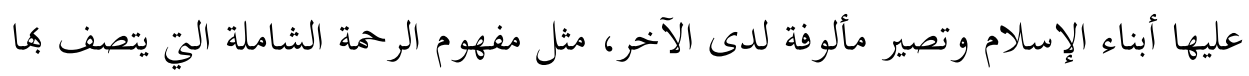

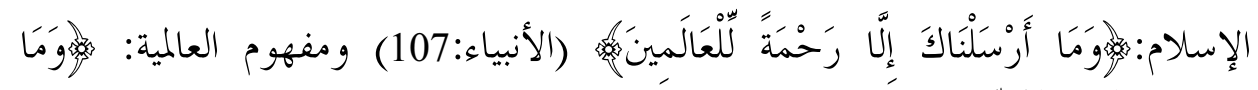

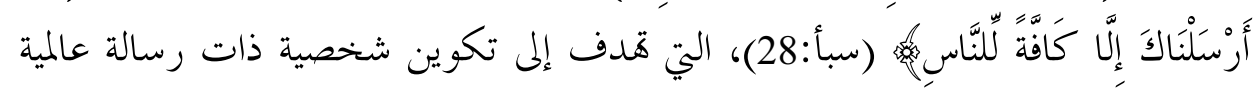


في الرؤية والتفكير والعمل، للوصول إلى صيغة "الإنسان الصالح" بلغة القرآن، ومفهوم

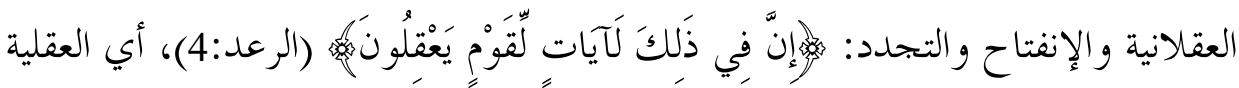

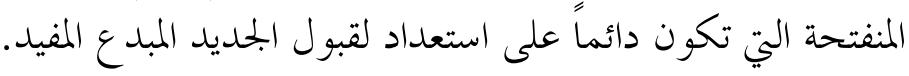

إلى جانب إصلاح شخصية المسلم، لابد من إدراك المعطيات الدولية والتعامل

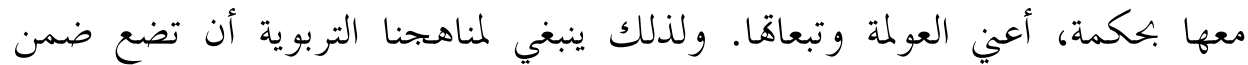

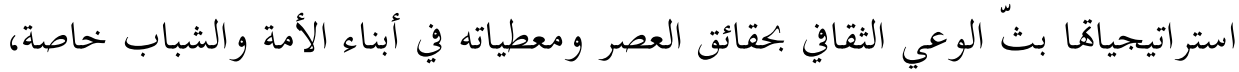
وإدراك دور وسائل الإعلام والاتصالات وأهميتها في العملية التربوية؛ والسعي لبناء

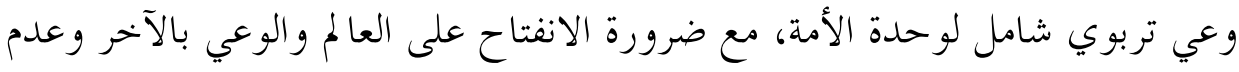

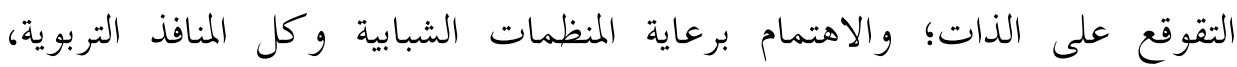

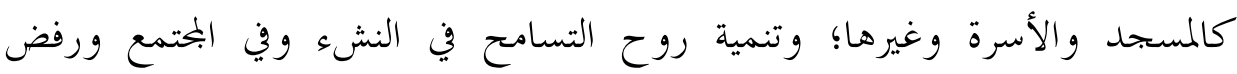

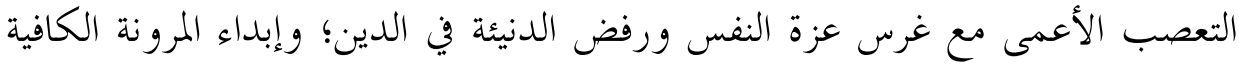
في سياسة التعامل مع المعطيات الدولية وإفرازاتا وتحدياتا وتفادي المواجهات التهات السافرة. وفي الحتتام يمكن القول إن أهم ملحظ للباحث في موضوع "التربية" هو كثرة

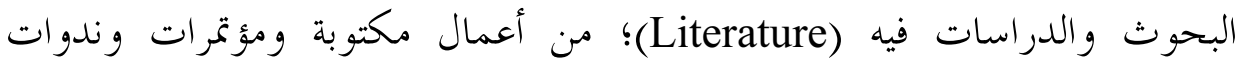

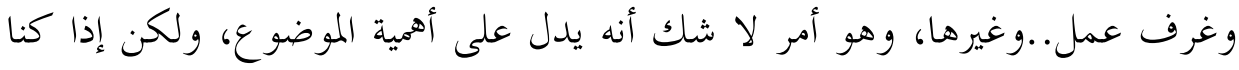

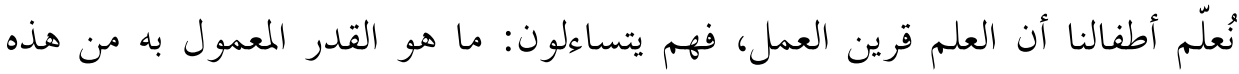

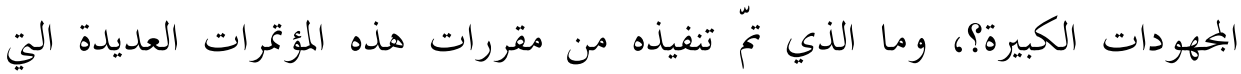

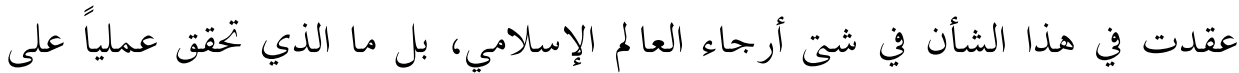

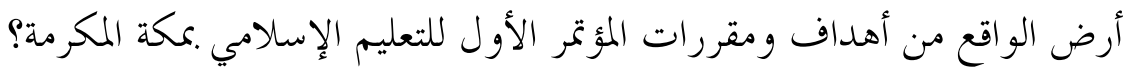
ليس القصد هنا الدعوة لإيقاف هذه الأعمال والمؤتمرات، بقدر ما هي دعوة

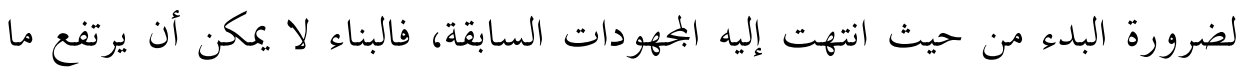

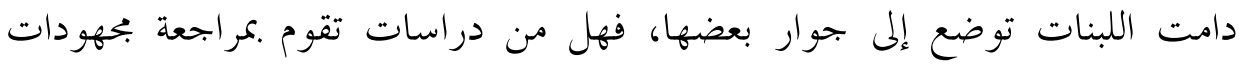

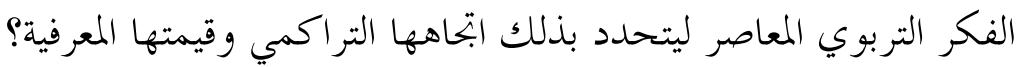

